\title{
Arctic climate and its interaction with lower latitudes under different levels of anthropogenic warming in a global coupled climate model
}

\author{
Torben Koenigk ${ }^{1,3}$ (1) $\cdot$ Laurent Brodeau $^{2,3}$
}

Received: 19 October 2015 / Accepted: 7 September 2016 / Published online: 20 September 2016

(C) The Author(s) 2016. This article is published with open access at Springerlink.com

\begin{abstract}
Three quasi-equilibrium simulations using constant greenhouse gas forcing corresponding to years 2000, 2015 and 2030 have been performed with the global coupled model EC-Earth in order to analyze the Arctic climate and interactions with lower latitudes under different levels of anthropogenic warming. The model simulations indicate an accelerated warming and ice extent reduction in the Arctic between the year-2030 and year-2015 simulations compared to the change between the year-2015 and year-2000 simulations. Both Arctic warming and sea ice reduction are closely linked to the increase of ocean heat transport into the Arctic, particularly through the Barents Sea Opening. Decadal variations of Arctic sea ice extent and ice volume are of the same order of magnitude as the observed ice extent reductions in the last 30 years and are dominated by the variability of the ocean heat transports through the Barents Sea Opening and the Bering Strait. Despite a general warming of mid and high northern latitudes, a substantial cooling is found in the subpolar gyre of the North Atlantic under year-2015 and year-2030 conditions. This cooling is related to a strong reduction in the AMOC, itself due to reduced deep water formation in the Labrador Sea. The observed trend towards a more negative phase of the North Atlantic Oscillation (NAO) and the observed linkage between autumn Arctic ice variations and NAO are
\end{abstract}

Torben Koenigk

torben.koenigk@smhi.se

1 Rossby Centre, Swedish Meteorological and Hydrological Institute, 60176 Norrköping, Sweden

2 Department of Meteorology, Stockholm University, 10691 Stockholm, Sweden

3 Bolin Centre for Climate Research, Stockholm University, 10691 Stockholm, Sweden reproduced in our model simulations for selected 30-year periods but are not robust over longer time periods. This indicates that the observed linkages between ice and NAO might not be robust in reality either, and that the observational time period is still too short to reliably separate the trend from the natural variability.

Keywords Arctic climate change - Climate variability . Global climate modelling · Coupled simulations · Arcticlower latitude interactions

\section{Introduction}

Observations of the last decades indicated that Arctic near surface temperature trends were about twice the rate of the global mean warming in the last decades (Stocker et al. 2013; Richter-Menge and Jeffries 2011). Different processes have been suggested to contribute to this amplified warming signal including the ice albedo feedback (Serreze et al. 2009; Screen and Simmonds 2010a, b), changes in clouds and water vapour (Graversen and Wang 2009; Liu et al. 2008), enhanced meridional energy transport in the atmosphere (Graversen et al. 2008) and the ocean (Spielhagen et al. 2011; Koenigk and Brodeau 2014), vertical mixing in Arctic winter inversion (Bintanja et al. 2011) and temperature feedbacks (Pithan and Mauritsen 2014). Sea ice cover and volume have dramatically been reduced in the last decades (Comiso et al. 2008; Devasthale et al. 2013) and also land snow cover has been subject to changes with an earlier onset of the snow melt and reduction of summer snow extent (Brown and Robinson 2011).

Variations of snow and ice cover have a large influence on local and remote climate conditions (Magnusdottir et al. 2004; Alexander et al. 2004; Kvamstö et al. 2004; Koenigk 
et al. 2009) and a number of recent studies suggested linkages between the recent sea ice loss and mid-latitude weather and climate extremes (Petoukhov and Semenov 2010; Francis et al. 2009; Francis and Vavrus 2012; Yang and Christensen 2012; Overland and Wang 2010; Hopsch et al. 2012; Garcia-Serrano and Frankkignoul 2014; Liptak and Strong 2014; Koenigk et al. 2016). Most of these studies found that reduced autumn ice extent leads to an atmospheric winter circulation that resembles the negative phase of the North Atlantic Oscillation (NAO). Particularly, eastern Europe and central Asia might respond with cold winter temperature anomalies to the autumn sea ice decline.

However, controversy exists regarding amplitude and robustness of the signal (Screen 2014; Barnes 2013; Barnes and Screen 2015). The relatively short time series of reliable sea ice data, together with a climate in transition makes the interpretation of possible linkages between sea ice reduction and mid-latitude climate extremes difficult. Analysis of long observational based time series and model simulations showed that the relation between the NAO and Arctic climate variables, as surface temperature, sea ice and oceanic heat transports, is not robust over time (Goosse and Holland 2005).

Changes in Arctic climate variations could also affect lower latitudes via oceanic linkages. The export of freshwater out of the Arctic alters the deep water formation in the North Atlantic (Häkkinen 1999; Haak et al. 2003; Koenigk et al. 2006). Dickson et al. (1988) and Belkin et al. (1998) suggested that the so called "Great Salinity Anomalies" in the 70s and 80s were mainly caused by strong ice exports through Fram Strait. Such variations in the Arctic freshwater exports have also the potential to affect the variability of the Atlantic Meridional Overturning Circulation (AMOC).

The ongoing Arctic climate change is superimposed by large interannual to multi-decadal variations. This lowfrequency variability makes it difficult to extract the Arctic warming and its impact on lower latitudes due to anthropogenic warming from the observations. Screen et al. (2014) showed that Arctic internal variability can mask the sign of the response to Arctic sea ice decline.

In this study, we analyze three 100 -year long climate simulations, using different constant external forcing, with a successor of the CMIP5 version of the EC-Earth global climate model. We aim to investigate the extent to which the Arctic climate responds to changes in the external forcing, and if we can learn something about the robustness of the observed Arctic climate changes and the suggested linkages to lower latitudes.

The article is organized as follows: following this introduction, the model and the simulations are described. Section 3 presents the results and Sect. 4 provides a summary and conclusions from this study.

\section{Model and simulations}

\subsection{Model description}

The model used in this study is the version 3.0.1 of the global coupled climate model EC-Earth (Hazeleger et al. 2010, 2012; Sterl et al. 2012), which is the successor of version 2.3 used for CMIP5, and which was also used by Batté and Doblas-Reyes (2015) and Davini et al. (2015). Compared to version 2.3, EC-Earth3.0.1 includes updated versions of its atmospheric and oceanic model components, as well as a higher horizontal and vertical resolution in the atmosphere.

The atmospheric component of EC-Earth is the Integrated Forecast System (IFS) of the European Centre for Medium Range Weather Forecasts (ECMWF). Based on cycle $36 \mathrm{r} 4$ of IFS, it is used at a T255 resolution, using a reduced Gauss-grid. The model has 91 vertical levels, thereof 50 above $200 \mathrm{hPa}$. The model top is at $0.01 \mathrm{hPa}$.

The ocean component is the Nucleus for European Modelling of the Ocean (NEMO, Madec 2008). It uses a tri-polar grid with poles over northern North America, Siberia and Antarctica with a resolution of about 1 degree (the so-called ORCA1-configuration) and 46 vertical levels (compared to 42 levels in the CMIP5 model version). The upper model level is at about $3 \mathrm{~m}$ and 10 levels are in the upper $100 \mathrm{~m}$. The ocean model is based on NEMO version 3.3.1 and includes the Louvain la Neuve sea-ice model version 3 (LIM3, Vancoppenolle et al. 2012), which is a dynamic-thermodynamic sea-ice model. EC-Earth3.0.1 uses LIM3 with only one sea ice category. The atmosphere and ocean/sea ice parts are coupled through the OASIS (Ocean, Atmosphere, Sea Ice, Soil) coupler (Valcke 2006) every three hours.

\subsection{Simulations}

Three 100-year long simulations with EC-Earth were performed, forced with three different constant greenhouse gas concentrations corresponding to year 2000 (EXP2000), 2015 (EXP2015) and 2030 (EXP2030), respectively. Concentration levels for year 2000 are based on observations; for years 2015 and 2030, the respective levels from the RCP4.5 emission scenario have been used. The $\mathrm{CO}_{2}$ concentration used in EXP2000 is the observed value from year 2000 of 368.87 ppm; in EXP2015 and EXP2030, $399.97 \mathrm{ppm}$ and $435.05 \mathrm{ppm}$ are used, respectively. The $\mathrm{CO}_{2}$ increase between EXP2030 and EXP2015 is thus slightly larger than the increase between EXP2015 and EXP2000. However, because of the logarithmical increase of the radiative forcing with increased $\mathrm{CO}_{2}$ concentration, the increase in radiative forcing is nearly linear across our 
simulations. All three simulations were started from the same initial conditions obtained from the end of a 200-year long present day (using constant year 2000 forcing) control simulation. EXP2000 is a continuation of this present day control simulation using exactly the same model version and configurations.

For most of the analysis, year 21-100 of the simulations are used; the first 20 years are disregarded to allow the model to adjust to the modified external forcing. Results from existing studies (Döscher et al. 2010, Tietsche et al. 2011) indicated that near surface variables, as e.g. sea ice, recover from initial shocks within about one decade. Our EXP2000 simulation is in total 300 year long and even the deep ocean is in good equilibrium (see Fig. 1). This indicates that trends at the surface, and probably even in the AMOC, are mainly caused by natural variations and are not due to model drift in EXP2000. EXP2015 shows very small trends in Arctic T2m $(-0.07 \mathrm{~K} / 80$ years) and SST (0.045 K/80 years), AMOC (0.24 Sv/80 years) and Arctic sea ice parameters (see Sect. 3.2; September ice extent trend: $-1.6 \times 10^{10} \mathrm{~m}^{2} / 80$ years). The trends in EXP2015 are smaller than the trends in EXP2000, except for the deep ocean where we find a small drift of $0.03 \mathrm{~K}$ in 100 years. Given the fact, that EXP2000 is in equilibrium in the deep ocean, the trends in EXP2000 are probably mainly due to internal variability. Since the trends are smaller in EXP2015 than in EXP2000, we conclude that the drift in EXP2015 due to the initialization is small, and is no problem for the analysis in this study. In EXP2030, the trends are larger and the trend of the global mean SST reaches $0.24 \mathrm{~K} / 80$ years. Arctic temperature and the AMOC show a positive trend and the Arctic sea ice extent a negative trend. Most of these trends are related to a sudden warming in both the Arctic and the global mean after year 60 (Fig. 1a, b). It remains unclear if this warming is due to natural variability or a late response to the changes in the external forcing. In order to estimate the effect of the trends on the correlation between different variables in our simulations, we also performed all correlation analyses with detrended data. However, this had only a small effect on the results. Only in EXP2030, we see slightly reduced values for most of the correlations.

Note: our 100-year time series are too short to analyze multi-decadal variations in the ocean in detail. However, they allow to estimate the mean Arctic climate change caused by changes in the greenhouse gas forcing, and they allow to investigate the possible linkages between the Arctic and lower latitudes, and how these linkages might change under different greenhouse gas forcings.

Variations of the sea ice edge affect the atmosphere locally and possibly remotely. In a transient climate, the sea ice edge moves to the north with superimposed variations, which makes it almost impossible to extract the atmospheric response to the sea ice change from the sea ice variability. Note: our simulations differ only in the greenhouse-gas forcing. All other external forcings are the same in all three simulations. Thus, in contrast to observations and transient model simulations, our work really focuses on the differences caused by changes in the greenhouse-gas forcing.

\section{Results}

The CMIP5 version of EC-Earth simulates slightly too cold global mean sea surface temperatures (Sterl et al. 2012) and a cold bias of about $2 \mathrm{~K}$ in the Arctic for present day conditions (Koenigk et al. 2013). This cold bias is slightly less pronounced in version 3.0.1 used in the present study (Table 1). In our EXP2000, EXP2015 and EXP2030 simulations, the global mean sea surface temperature (SST) reaches, averaged over the last 80 years, 18.18, 18.32 and $18.55^{\circ} \mathrm{C}$, respectively (Table 1 ). This compares to a SST of $18.57{ }^{\circ} \mathrm{C}$ in HADISST and $18.51{ }^{\circ} \mathrm{C}$ in ERA-interim for the period 1980-2013.

As for the global mean SST, Arctic mean $2 \mathrm{~m}$ air temperature (T2m) in EXP2030 (Fig. 1a) agrees best to the 1980-2013 period in the reanalysis data. However, due to sparse observations in the Arctic, uncertainties in reanalyses data are considerable as well (Jakobson et al. 2012). Jakobson et al. (2012) compared different reanalysis data sets in the Arctic and concluded that ERA-interim performs best. However, there is a tendency for a warm bias of locally up to $2 \mathrm{~K}$ in ERA-interim below $400 \mathrm{~m}$.

The warming in the Arctic (Table 1) is amplified compared to the global mean T2m values $(0.21 \mathrm{~K}$ in EXP2015 and $0.58 \mathrm{~K}$ in EXP2030) by a factor of about three and reaches $1.78 \mathrm{~K}$ in EXP2030. This compares to an observed Arctic warming of about $2 \mathrm{~K}$ since 1980. As for global mean values, the warming is stronger between EXP2030 and EXP2015 compared to the difference between EXP2015 and EXP2000. This agrees well with findings from Gregory et al. (2002) and Mahlstein and Knutti (2012).

All three simulations exhibit large decadal variations in a number of variables (Fig. 1). However, the mean changes of the variables in Fig. 1 are all significant at the $95 \%$ significance level. To calculate the significance, we used a two-sided student $t$ test and we calculated decorrelationtimes to estimate the number of degrees of freedom (von Storch and Zwiers 1999).

\subsection{Ocean}

The spatial distribution of sea surface temperature (SST) and its changes in EXP2015 and EXP2030 compared to 
(a) Arctic $2 \mathrm{~m}$ air temperature $\left(70-90^{\circ} \mathrm{N}\right)$

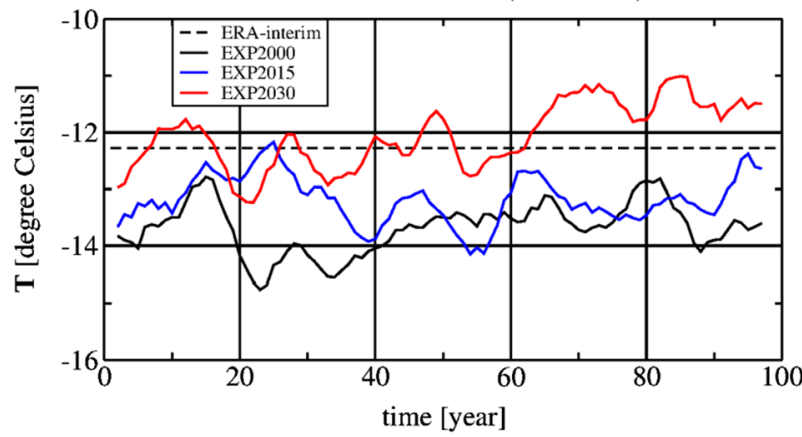

(b) Global mean SST

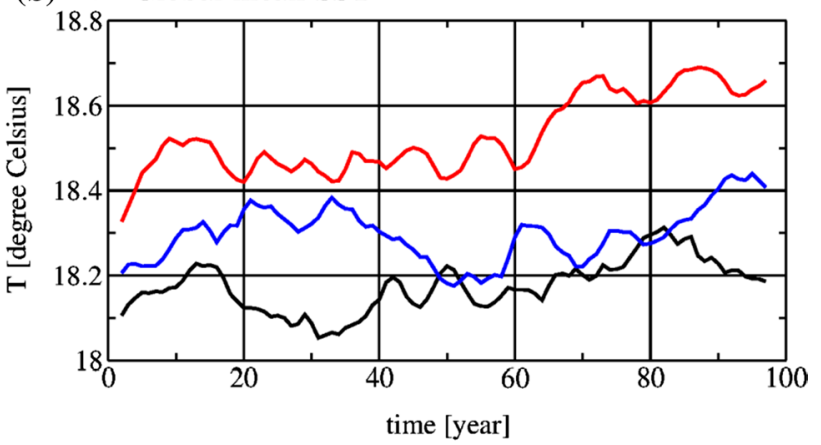

(c) Global mean ocean temperature, $1000 \mathrm{~m}$ - bottom

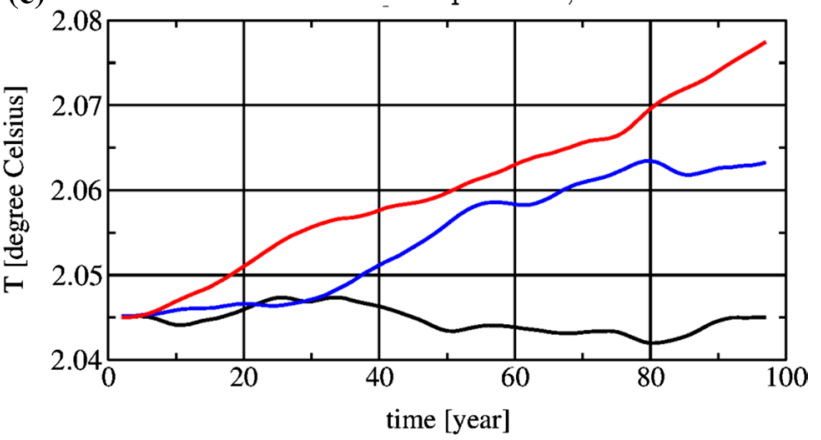

(d) Max of $\mathrm{AMOC}$

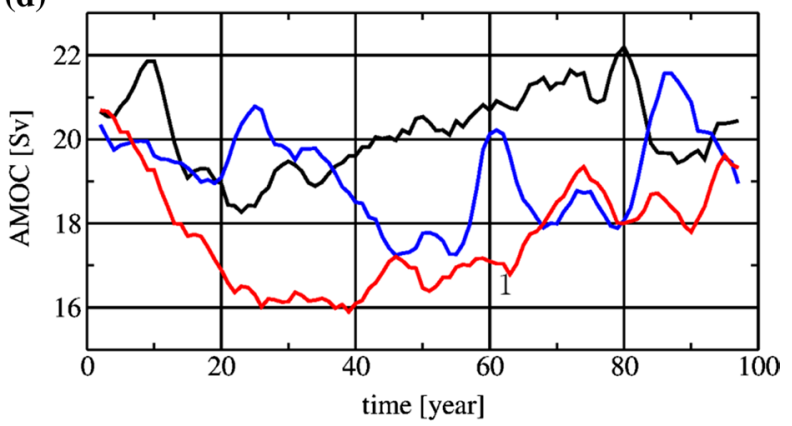

Fig. 1 a Five-year running mean $2 \mathrm{~m}$ air temperature in ${ }^{\circ} \mathrm{C}$, averaged over $70^{\circ}-90^{\circ} \mathrm{N}$ in EXP2000 (black), EXP2015 (blue) and EXP2030 (red). The dashed black line shows the mean $2 \mathrm{~m}$ air temperature from ERA-interim, averaged over 1980-2013. b Five-year running mean global mean sea surface temperature (SST) in ${ }^{\circ} \mathrm{C}$. c Five-year running mean of global mean ocean temperature in ${ }^{\circ} \mathrm{C}$, averaged over $1000 \mathrm{~m}$ to the bottom. d Five-year running means of maximum AMOC in $\mathrm{Sv}$ in EXP2000 (black), EXP2015 (blue) and EXP2030 (red)
EXP2000 in mid and high northern latitudes are presented in Fig. 2a-c. The main discrepancy from observed present day SST is a cold bias of several $\mathrm{K}$ in the sub-polar gyre. This cold bias is a typical problem of coarse resolution ocean models (Large and Danabasoglu 2006; Eden et al. 2004) and is due to a North Atlantic Current that is too zonal and misplaced to the south (see discussion in Sterl et al. 2012). The SST change in EXP2015 is dominated by a strong cooling in an area south of Greenland. In the Labrador Sea and the northeastern North Atlantic, surface temperature rises significantly, with up to $2 \mathrm{~K}$ northeast of Iceland. The North Pacific SST increases with up to $0.5 \mathrm{~K}$. In EXP2030, the amplitude of the anomalies grows but the pattern remains similar. Meanwhile, the cooling south of Greenland gets even more pronounced. The changes of SST strongly affect the turbulent surface heat fluxes between the ocean and the atmosphere (sum of latent and sensible heat fluxes, $\mathrm{Q}_{\mathrm{TLA}}$, positive means heat flux into the ocean, Fig. 3). For instance, over the cooling area in the North Atlantic, significantly positive $\mathrm{Q}_{\mathrm{TLA}}$ anomalies occur, which means that less heat is released to the atmosphere. East of this area, negative $\mathrm{Q}_{\mathrm{TLA}}$ anomalies occur, reflecting increased SST. In addition to the effects of changes in SST, changes in the atmospheric temperature might contribute to modified vertical temperature gradients and changes in $\mathrm{Q}_{\mathrm{TLA}}$.

Many future climate projections showed the smallest warming south of Greenland (Stocker et al. 2013) but only very few models simulated a significant cooling as found in our study. Also transient future climate projections with EC-Earth2.3 showed reduced warming but no cooling in this area (Koenigk et al. 2013). Observational based data, however, show a significantly negative temperature trend in this area south of Greenland (Rahmstorf et al. 2015), widely debated as the "Atlantic cold blob". Rahmstorf et al. (2015) related this cooling to a reduction in the AMOC, especially after 1970 . The strong cooling in our model might partly be due to the constant forcing as opposed to the transient forcing in CMIP5. The AMOC (Fig. 1b) and the associated oceanic northward heat transports vary on multi-decadal time scales. Thus, the transient year 2030 climate is affected by ocean water masses that have been formed decades before, in a climate with still high AMOC activity. In our experiments, the use of a constant forcing might increase the cooling effect from changes in the northward oceanic heat fluxes compared to the increased greenhouse gas forcing in transient climate simulations. All three experiments show large variations and a tendency to a weakening of the AMOC in the first two decades, particularly in EXP2030. Thereafter, the AMOC increases again but its average stays about $3 \mathrm{~Sv}$ smaller in EXP2030 than in EXP2000; also in EXP2015 a significant reduction occurs (compare Table 1). This reduction in 
Table 1 Mean values and standard deviations (cursive) for the years 21-100 of annual mean Arctic T2m, global mean SST, September and March Arctic ice extent and volume and annual mean max

\begin{tabular}{lcccc}
\hline Mean (years 21-100); & EXP2000 & EXP2015 & EXP2030 & Observation/Estimation \\
Standard-deviation & & & \\
\hline Annual mean T2m Arctic (70 -90 N) in ${ }^{\circ} \mathrm{C}$ & -13.7 & -13.2 & -11.9 & -12.3 (ERAint) \\
& 0.58 & 0.60 & 0.73 & 0.58 (detrended) \\
Annual mean global mean SST in ${ }^{\circ} \mathrm{C}$ & 18.18 & 18.32 & 18.55 & 18.51 (ERAint); 18.57 (HADISST) \\
& 0.07 & 0.08 & 0.10 & 0.06 (detrended) \\
NH ice extent September in $10^{6} \mathrm{~km}^{2}$ & 8.11 & 7.72 & 6.80 & 6.73 (NSIDC) \\
& 0.58 & 0.56 & 0.65 & 0.48 (detrended) \\
NH ice extent March in $10^{6} \mathrm{~km}^{2}$ & 14.32 & 14.04 & 13.53 & 15.60 (NSIDC) \\
& 0.32 & 0.33 & 0.40 & 0.51 (detrended) \\
NH ice volume September in $10^{3} \mathrm{~km}^{3}$ & 15.0 & 12.49 & 9.92 & 12.5 (PIOMAS) \\
& 2.19 & 2.20 & 1.82 & 1.52 (detrended) \\
NH ice volume March in $10^{3} \mathrm{~km}^{3}$ & 24.6 & 22.40 & 19.38 & 28.0 (PIOMAS) \\
Annual mean max AMOC in Sv & 1.94 & 1.98 & 1.85 & 1.15 (detrended) \\
\end{tabular}

The standard deviations of the observations have been calculated using detrended data

our quasi-equilibrium simulations is almost three times as large as the AMOC reduction between year 2030 and year 2000 in transient CMIP5 projections with EC-Earth, and as large as the change until the second half of the twenty-first century in the CMIP5 simulations (Brodeau and Koenigk 2015). Towards the end of our 100-year simulations, the differences between the three simulations decrease. While part of this reduction is due to relatively low AMOC values in the last 20 years of EXP2000, we cannot rule out that a partial recovery of the AMOC in EXP2015 and EXP2030 contributes as well. Results by Blackport and Kushner (2016) indicated a recovery of an initial AMOC-reduction to Arctic sea ice loss after a few 100 years. Our experiment setup differs substantially from the experiments done by Blackport and Kushner (2016) but our time series are too short to see if a similar AMOC-recovery would take place. A partial recovery of the AMOC would likely lead to a less pronounced cold temperature blob.

The sea surface salinity (SSS) is strongly reduced in the same area of the North Atlantic where the ocean surface is getting cooler (Fig. 2d-f). Again, this is likely the consequence of the reduced transport of warm and salty water masses into this region. Also in the Central Arctic, the surface gets significantly fresher, likely due to increased freshwater input from rivers and increased precipitation (Koenigk et al. 2007, 2013). The ocean circulation stores most of the additional freshwater in the Beaufort Gyre or transports it in the Transpolar Drift Stream towards Fram Strait. An increased freshwater storage in the Beaufort Gyre is in agreement with observations (Giles et al. 2012).
AMOC in EXP2000, EXP2015, EXP2030 and estimates for the recent past (1980-2013, 2004-2013 for RAPID-MOCCHA) 
SST change

(a) SST, EXP2000, YM

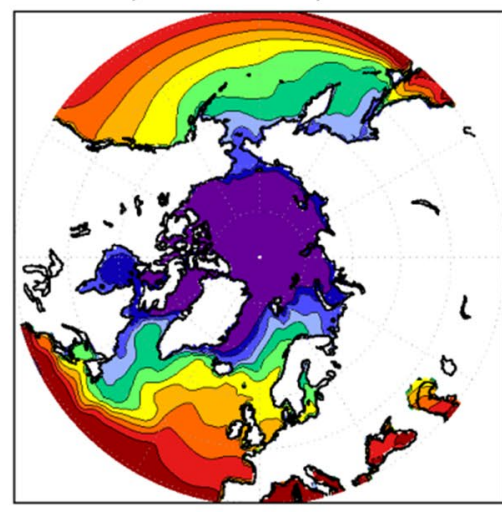

$\begin{array}{llllllllllll}-1 & 0 & 2 & 4 & 6 & 8 & 10 & 12 & 14 & 16 & 20\end{array}$ ${ }^{\circ} \mathrm{C}$

(d) SSS, EXP2000, YM

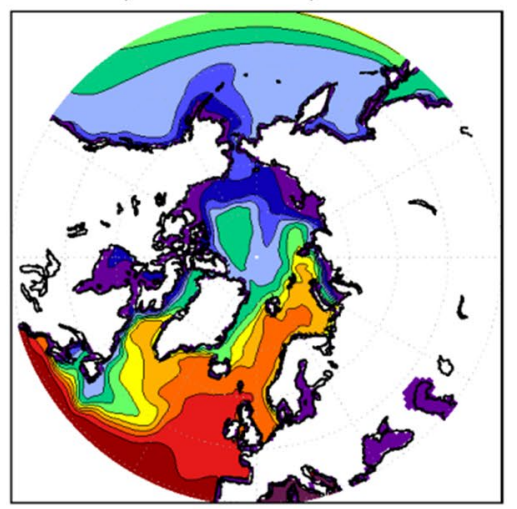

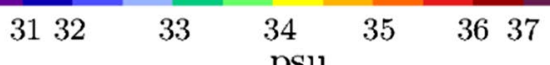

(g) MXLD, EXP2000, March

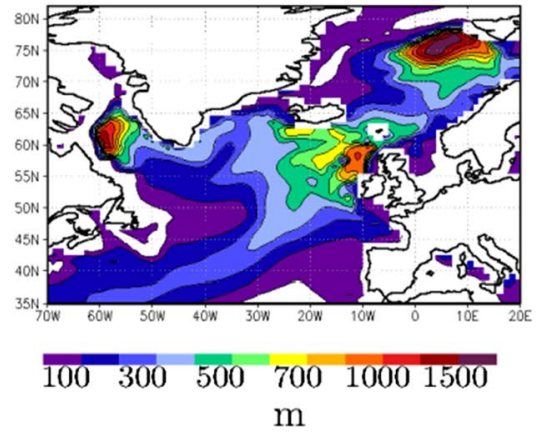

(b) EXP2015 - EXP2000, YM
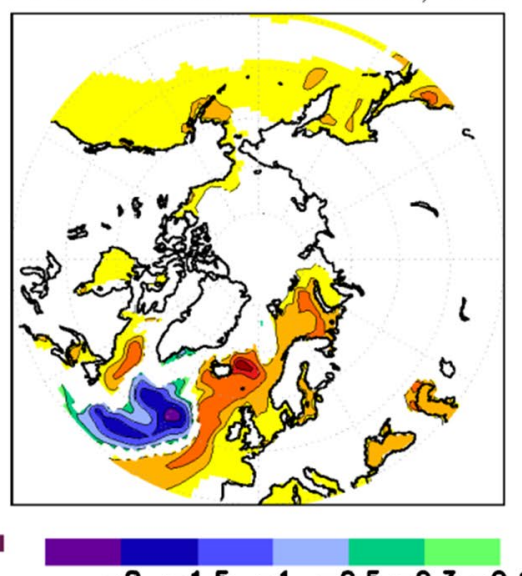

$\begin{array}{lllllll}-2 & -1.5 & -1 & -0.5 & -0.3 & -0.1 & 0.1\end{array}$

${ }^{\circ} \mathrm{C}$

(c) EXP2030 - EXP2000, YM

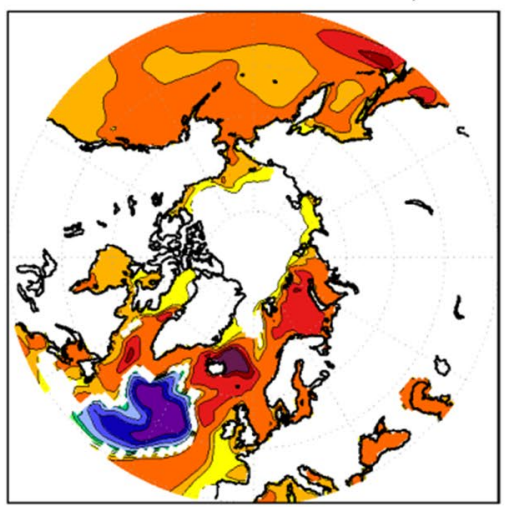

SSS change

(e) EXP2015 - EXP2000, YM

(f) EXP2030 - EXP2000, YM
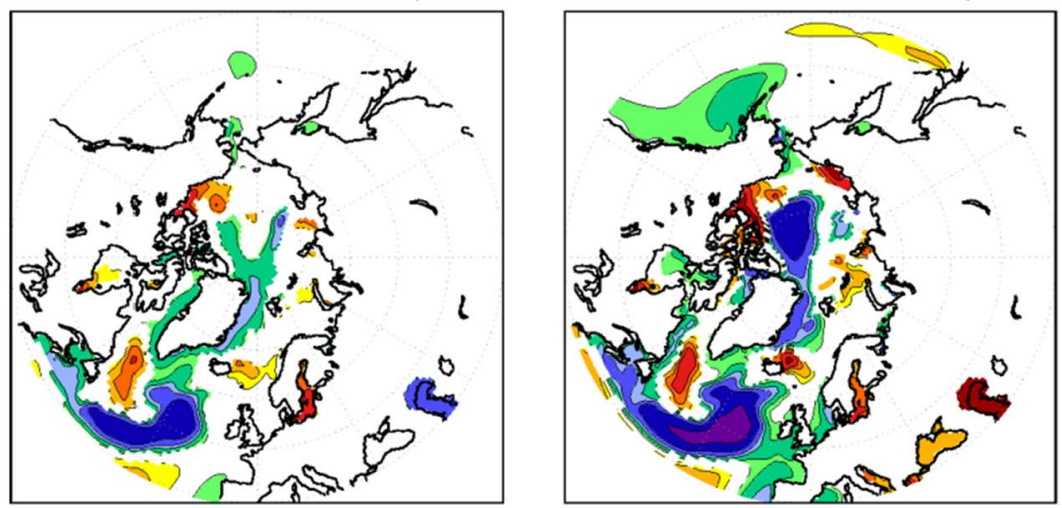

$\begin{array}{llllllllllll}-1 & -0.5 & -0.3 & -0.2 & -0.1 & -0.05 & 0.05 & 0.1 & 0.2 & 0.3 & 0.5 & 1\end{array}$

psu

MXLD change

(h) EXP2015 - EXP2000, March (i) EXP2030 - EXP2000, March
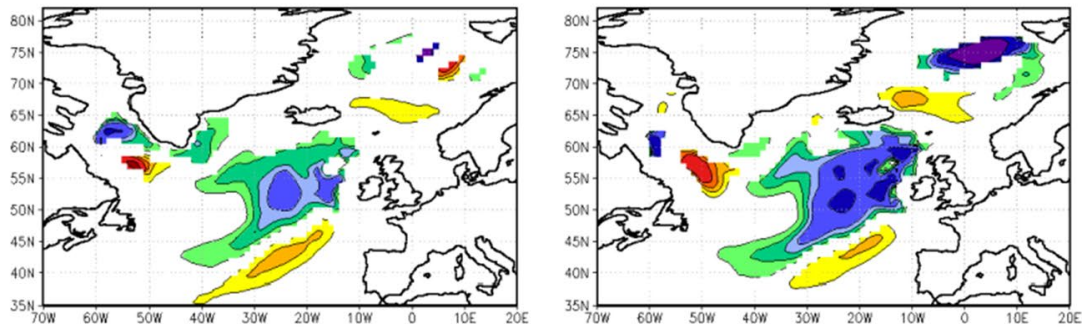

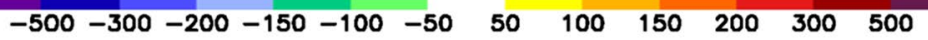
$\mathrm{m}$
Fig. 2 Annual mean sea surface temperature (SST) averaged over years 21-100 in EXP2000 (a) and its change in EXP2015 (b) and EXP2030 (c). d-f The same as a-c but for sea surface salinity (SSS). $\mathbf{g}-\mathbf{i}$ The same as $\mathbf{a}-\mathbf{c}$ but for mixed layer depth (MXLD). In $\mathbf{b}, \mathbf{c}, \mathbf{e}, \mathbf{f}$, $\mathbf{h}, \mathbf{i}$ only areas with significant changes exceeding the $95 \%$ level are shown as colored 
Fig. 3 Differences in turbulent surface heat flux $\left(\mathrm{Q}_{\mathrm{TLA}}\right)$ between EXP2015 and EXP2000 (a) and EXP2030 and EXP2000 (b) in winter (a, b) and summer (c, d). Positive values indicate fluxes into the ocean. Only areas with significant changes exceeding the $95 \%$ level are shown as colored

turbulent surface heat flux change

(a) EXP2015 - EXP2000, DJF

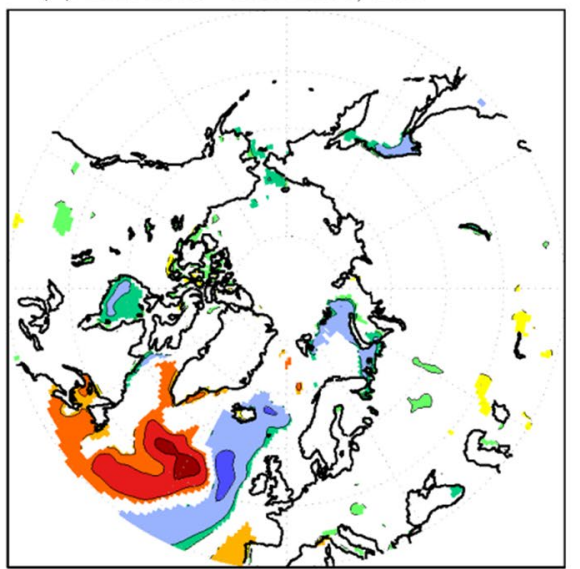

(c) EXP2015 - EXP2000, JJA

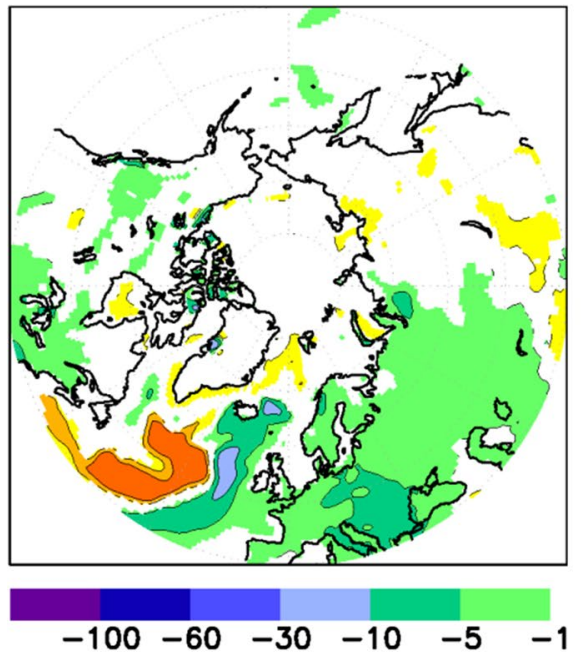

(b) EXP2030 - EXP2000, DJF

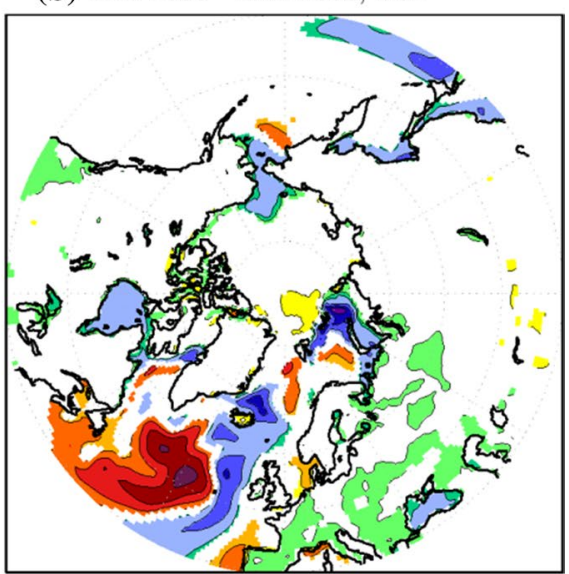

(d) EXP2030 - EXP2000, JJA

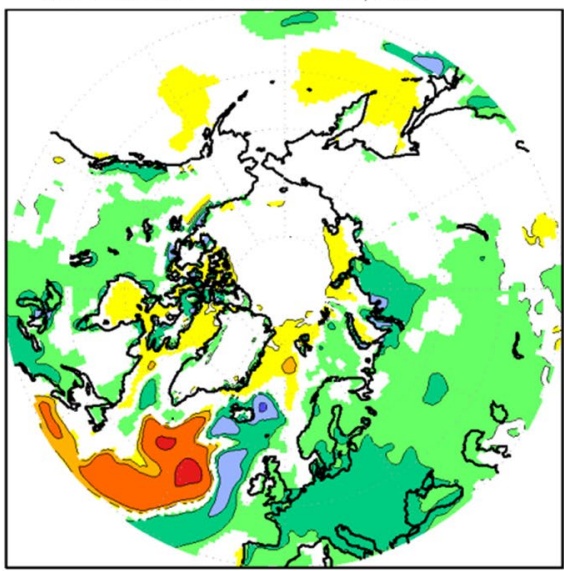

$\begin{array}{lllll}5 & 10 & 30 & 60 & 100\end{array}$ $\mathrm{W} / \mathrm{m}^{2}$

Brodeau and Koenigk (2015) but we have moved the box for the convective region of the Labrador Sea region used in Brodeau and Koenigk (2015) slightly to the northwest to capture the more realistic placement of the deep convection in EC-Earth3.0.1 compared to EC-Earth2.3. Figure 4a shows less frequent deep convective events in the Labrador Sea in EXP2015 compared to EXP2000 but the amplitude of the events is still similar. In EXP2030, however, both frequency and amplitude are substantially reduced. EXP2030 shows almost no deep convective activity between year 20 and 50 but a resurgence occurs from year 65 to 85 . The latter period falls together with the warming period in EXP2030. Brodeau and Koenigk (2015) found a highly significant correlation between decadal variations of the DMV in the Labrador Sea and the AMOC a few years thereafter. Also in our simulations, the DMV is clearly related to the AMOC. Indeed, almost every peak in the AMOC can be explained by deep convection in the Labrador Sea (compare Figs. $1 b$ and $4 a, c, e)$. The correlation between 11-year running mean values of the DMV and the AMOC reaches 0.68, 0.80 and 0.73 in EXP2000, EXP2015 and EXP2030, respectively (Table 2). The correlation is largest when the DMV leads the AMOC by 4 years and the significance exceeds the $95 \%$ significance level in all three simulations (using a student $t$ test and taking the smoothing of the time series into account). A detailed description of the linkages between the DMV and the AMOC and the causes for the DMV variability is given in Brodeau and Koenigk (2015).

Similar to the Labrador Sea, the MXLD in the Greenland Sea and in the Irminger Sea are strongly reduced. The DMV for the Greenland-Iceland-Norwegian Seas (GINSea, Fig. 4b, d, f) shows a strong reduction in amplitude, particularly in EXP2030, compared to EXP2000 and might contribute to a reduced AMOC as well. However, no clear relation between the variations of the DMV in the GINSea and the AMOC could be found (Figs. 1b, 4) and correlations are not significant. This might be explained by the less direct effect of the GIN-Sea bottom waters on the 
Fig. 4 Deep mixed volume (DMV) in the Labrador Sea (a, c, e) and in the GIN-Sea (b, d, f) in March in EXP2000 (a, b), $\operatorname{EXP} 2015(\mathbf{c}, \mathbf{d})$ and EXP2030 $(\mathbf{e}, \mathbf{f})$. Note that the scale is different for the Labrador Sea and the GIN-Sea
Labrador Sea
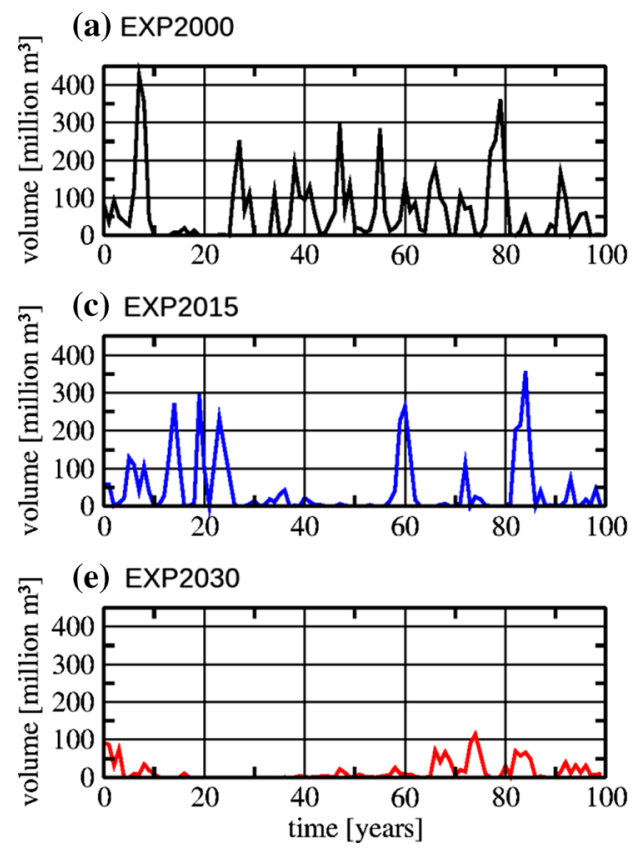

GIN-Sea

(b) EXP2000
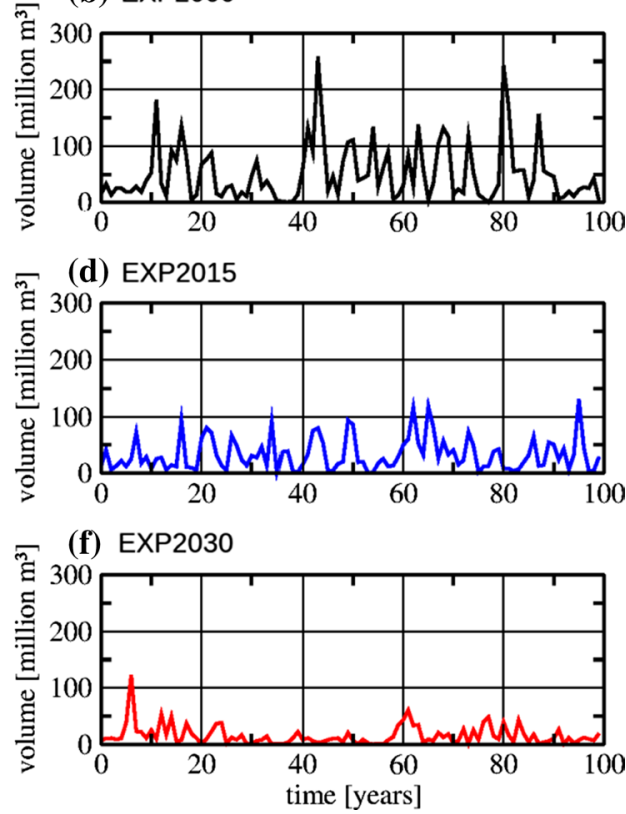

Table 2 Correlations calculated from 11-year running mean values

\begin{tabular}{|c|c|c|c|}
\hline Correlations, 11-year running means & EXP2000 & EXP2015 & EXP2030 \\
\hline $\begin{array}{l}\text { DMV Labrador Sea } \rightarrow \text { AMOC } \\
\text { DMV leads } 4 \text { years }\end{array}$ & $0.68(0.64)$ & $0.80(0.82)$ & $0.73(0.75)$ \\
\hline $\begin{array}{l}\text { DMV Labrador Sea } \rightarrow \text { T2m Arctic } \\
\text { DMV leads } 4 \text { years }\end{array}$ & $0.72(0.70)$ & $0.85(0.87)$ & $0.85(0.72)$ \\
\hline $\begin{array}{l}\mathrm{AMOC} \rightarrow \mathrm{BSO} \\
\operatorname{lag} 0\end{array}$ & $0.76(0.71)$ & $0.81(0.81)$ & $0.81(0.72)$ \\
\hline $\begin{array}{l}\text { AMOC } \rightarrow \text { Sep Arctic ice extent } \\
\text { lag } 0\end{array}$ & $-0.78(-0.74)$ & $-0.52(-0.55)$ & $-0.67(-0.73)$ \\
\hline $\begin{array}{l}\text { AMOC } \rightarrow \text { T2m Arctic } \\
\text { lag } 0\end{array}$ & $0.77(0.73)$ & $0.57(0.58)$ & $0.67(0.78)$ \\
\hline $\begin{array}{l}\text { Heat transport } \mathrm{BSO} \rightarrow \mathrm{T} 2 \mathrm{~m} \text { Arctic } \\
\text { lag } 0\end{array}$ & $0.78(0.74)$ & $0.85(0.85)$ & $0.92(0.79)$ \\
\hline Heat transport BSO $\rightarrow$ Sep Arctic ice extent lag 0 & $-0.86(-0.84)$ & $-0.81(-0.81)$ & $-0.87(-0.70)$ \\
\hline Heat transport Bering Strait $\rightarrow$ Sep Arctic ice extent, lag 0 & $-0.72(-0.68)$ & $-0.47(-0.50)$ & $-0.92(-0.91)$ \\
\hline
\end{tabular}

Cursive and bold numbers denote a correlation exceeding the 95 and $99 \%$ significance level, respectively. In brackets, the correlations of detrended time-series are shown

AMOC compared to the deep water that is formed in the Labrador Sea. During the complicated travel across the overflows towards the North Atlantic, the GIN-Sea bottom waters are more mixed with other water masses, and contribute thus less distinctly to the AMOC than the deep water that is formed in the Labrador Sea.

The ocean volume transports into the Arctic show pronounced decadal variations (Fig. 5, left). Both the inflow into the Arctic through the Barents Sea Opening (BSO) and the outflow through the Fram Strait are slightly increased in EXP2015 and EXP2030. However, the increase is small compared to the amplitude of the decadal variations. The heat transports through BSO and Fram Strait (Fig. 5, right) are substantially enhanced, particularly in EXP2030. The increase in the heat transport through BSO is partly due to the larger volume flux but is predominantly the consequence of warmer temperatures, which also explains the amplified increase in EXP2030. In contrast, the variations of the heat transport through BSO are mainly governed by variations in the volume transport. After year 60 , the heat transport through BSO in EXP2030 increases and stays at a higher level with reduced decadal variations. The volume 
Fig. 5 Five-year running mean ocean volume transports (a, c, $\mathbf{e}, \mathbf{g})$ and ocean heat transports $(\mathbf{b}, \mathbf{d}, \mathbf{f}, \mathbf{h})$ through the Arctic Straits and Openings in EXP2000 (black), EXP2015 (blue) and EXP2030 (red). Positive values show an input into the Arctic (a) Barents Sea Opening, volume flux

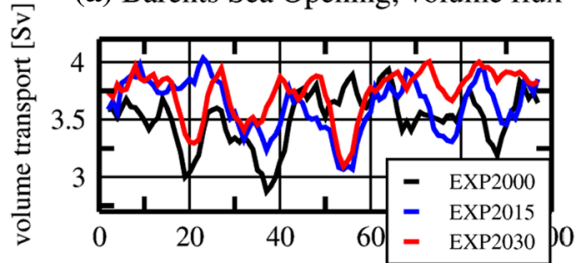

(c) Fram Strait, volume flux

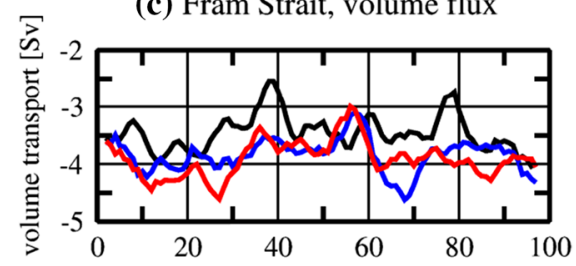

(e) Baffin Bay, volume flux

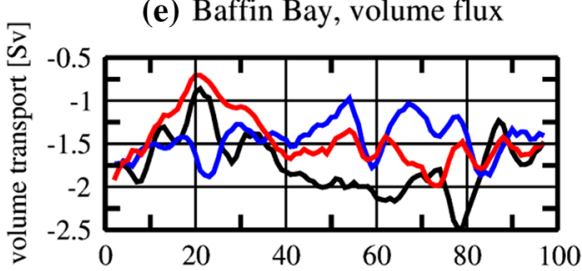

(g) Bering Strait, volume flux

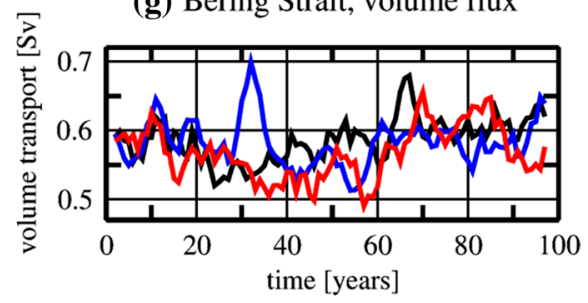

(b) Barents Sea Opening, heat flux

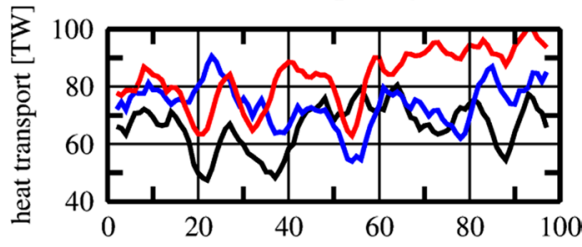

(d) Fram Strait, heat flux

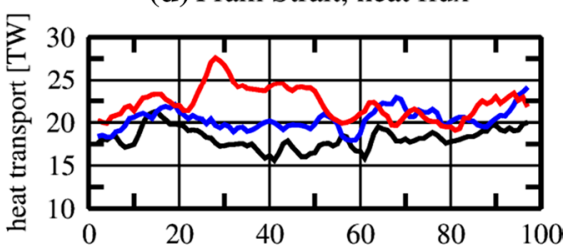

(f) Baffin Bay, heat flux

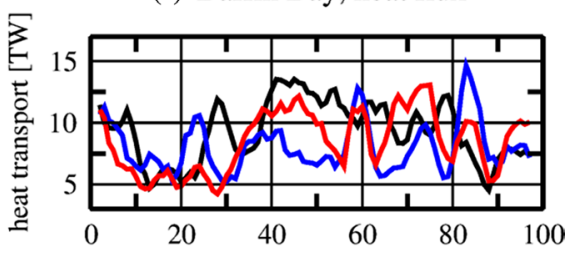

(h) Bering Strait, heat flux

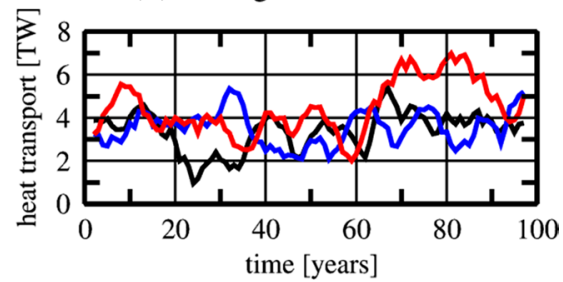

transport through BSO is also high in this period and its variability is small. In EXP2030, this increase in ocean heat transport into the Arctic coincides with the warming of the Arctic after year 60 (Fig. 1). In this period, the increased convective activity in the Labrador Sea and the resulting increase in the AMOC might contribute to the warmer temperatures and enhanced ocean transports through BSO as well. We find significant correlations between 11-year running means of the DMV in the Labrador Sea and the BSO heat transport and T2m in the Arctic (Table 2). Correlations between 11-year running means of the AMOC and the BSO heat transport also reach about 0.8 in all three simulations (Table 2) and the heat transport through BSO is highly correlated with the mean Arctic T2m. This underlines the importance of the ocean heat transport into the Arctic for both Arctic climate variation and change. However, beside the increasing heat transport through BSO after year 60, the heat transport through the Bering Strait is also very high between year 70 and 90 in EXP2030 and might contribute to the Arctic warming after year 60 .

Table 2 shows a significantly positive correlation between the AMOC and mean Arctic temperature. A possible explanation is that the AMOC affects the heat transport into the Arctic and thus consequently the Arctic sea ice and air temperature. As such, the reduction of the AMOC should have a dampening effect on the Arctic temperature in EXP2015 and EXP2030. By regressing the 11-year running mean values of the AMOC on the Arctic temperature in our three simulations, and taking the standard deviation of the AMOC into account, the reduction of the AMOC between EXP2030 and EXP2000 would lead to a reduction of the Arctic temperature increase by $0.6-1.1 \mathrm{~K}$. However, this assumes that the processes that link the variability of the AMOC with Arctic T2m are the same as the processes that relate the mean changes in the AMOC with the changes of Arctic T2m.

\subsection{Sea ice}

EC-Earth tends to underestimate the observed seasonal cycle of the sea ice extent (Fig. 6). The ice extent is lower than in NSIDC-data (average over 1980-2013; Cavalieri et al. 1996) in March but, except for EXP2030, higher in September. The ice extent difference between EXP2015 and EXP2000 is substantially smaller than the difference between EXP2030 and EXP2015. The simulated mean reduction between September ice extent in EXP2030 and EXP2000 reaches about 1.3 million $\mathrm{km}^{2}$ in our model 
Fig. 6 Five-year running mean of northern hemisphere ice extent in March (a) and September (b), northern hemisphere ice volume in March (c) and September (d). Five-year running mean ice transport through Fram Strait (e) and (f) annual cycle of Fram Strait ice export, averaged over years 21-100. Shown are EXP2000 (black), EXP2015 (blue), EXP2030 (red) and NSIDC ice extent data (dashed, averaged over 1980-2013) in $\mathbf{a}$ and $\mathbf{b}$ and PIOMAS ice volume data (dashed, averaged over 1980-2013) in $\mathbf{c}$ and $\mathbf{d}$ (a) ice extent March

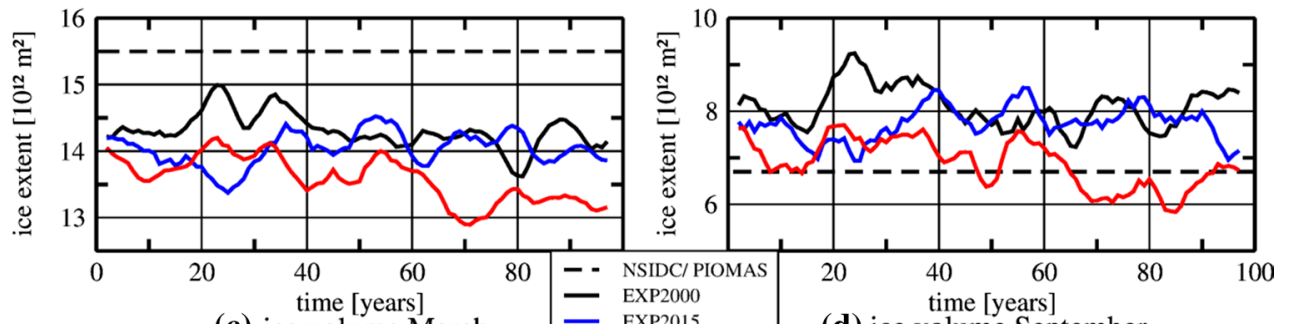

(c) ice volume March

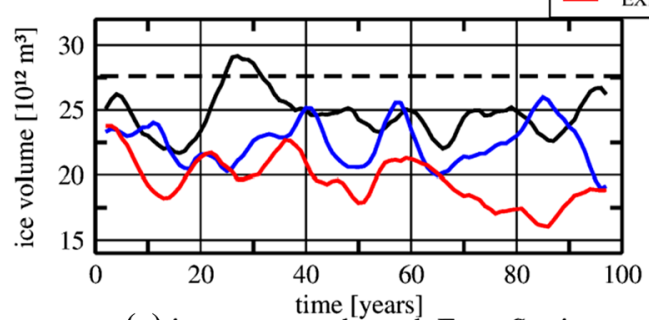

(e) ice transport through Fram Strait

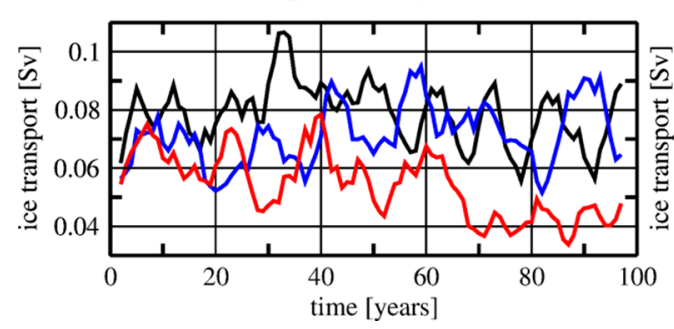

(b) ice extent September

(d) ice volume September

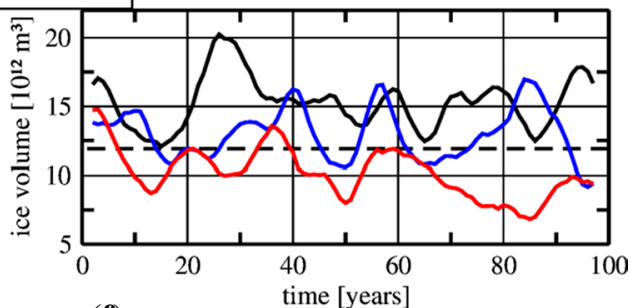

(f) Fram Strait ice export: annual cycle

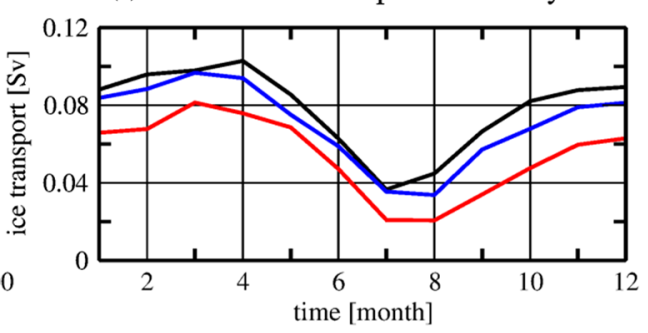

simulations and thus accounts for less than half of the observed reduction since 1980 .

The simulated ice volume loss is quite large (from 15 to 9.9 million $\mathrm{km}^{3}$ ) but also smaller than estimates for the real ice volume reduction. However, sea ice extent and volume in the Arctic (Fig. 6) show pronounced decadal-scale variations in our simulations. These variations could mask or enhance human-induced trends at interannual to decadal scales. This finding is in agreement with a recent study by Swart et al. (2015) analyzing the internal sea ice variability in CMIP5 models.

Not only the ice reduction but also the simulated T2m increase in the Arctic in EXP2030 $(1.78 \mathrm{~K})$ is smaller than in ERA-interim since 1980 (about 2 K). Still, it seems that Arctic sea ice in our model might respond less sensitively to global warming than in reality.

Sea ice extent in EXP2030 is reduced after year 60, which is consistent with the warm Arctic temperature after year 60. As discussed in Sect. 3.1, the ocean heat transports into the Arctic through both the Barents Sea Opening and Bering Strait are high after year 60. Increased ocean heat fluxes through these sections are likely to reduce the Arctic sea ice extent as shown by previous observational (Schlichtholz 2011, Woodgate et al. 2010) and modelling studies (Koenigk and Brodeau 2014). We find a strongly negative correlation, exceeding -0.8 in all three experiments (Table 2), between the low-pass filtered (11-year running means) heat transport through BSO and the Arctic sea ice extent in September. The relation between the heat transport through the Bering Strait and sea ice extent seems to be more variable, the correlations vary substantially between the three simulations (Table 2).

Similar to the ice extent, the amplitude of the annual cycle of ice volume seems to be slightly underestimated in our EC-Earth simulations. However, note that ice thickness observations are still extremely uncertain and that the reference data from the Pan-Arctic Ice Ocean Modeling and Assimilation System (PIOMAS, Zhang and Rothrock 2003) used here should not be considered as the truth. In contrast to sea ice extent and air temperature, sea ice volume (Fig. 6c, d) is already considerably reduced between EXP2015 and EXP2000, and no clear acceleration until 2030 can be seen. This might indicate that the sea ice first has to be thinned down to a critical thickness before the ice extent is substantially reduced. This is partly in contrast to results from Holland et al. (2006), who linked the rate of summer ice retreat mainly to the interplay of simulated natural variability and forced changes. In agreement to our study, Holland et al. (2006) found an important influence of the ocean heat transport into the Arctic on sea ice variability and decline.

The ice export out of the Arctic constitutes an important linkage between the Arctic and lower latitudes by its influence on the deep water formation in the North Atlantic, 


\section{ice concentration change}

(a) OSISAF, March

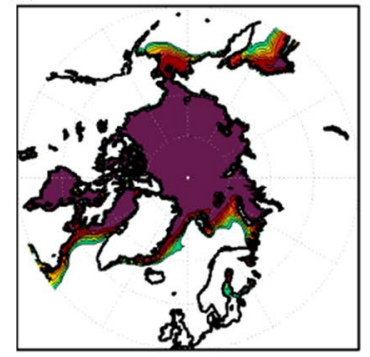

(e) OSISAF, September

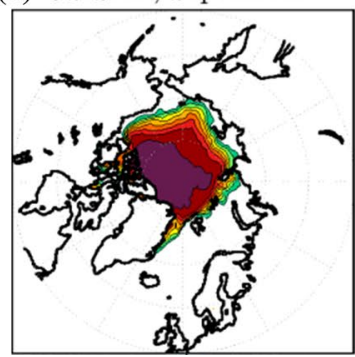

(b) EXP2000, March

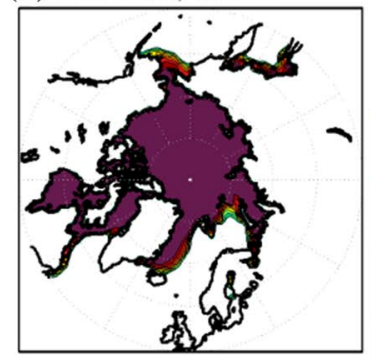

(f) EXP2000, September (c) EXP2015 - EXP2000

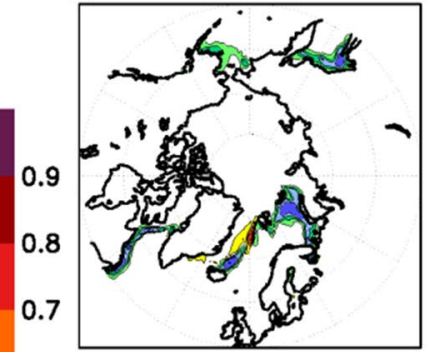

0.6(g) EXP2015 - EXP2000 (d) EXP2030 - EXP2000

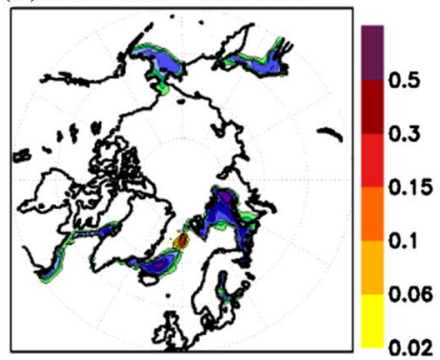

(h) EXP2030 - EXP2000

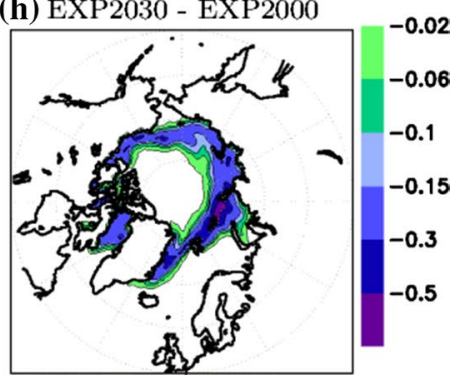

Fig. 7 Sea ice concentration averaged over years 21-100 in EXP2000 in March (b) and September (f) and sea ice concentration in the OSISAF satellite data set averaged over 1980-2013 (a, e). c, g Differences in sea ice concentration between EXP2015 and EXP2000 in March (c) and September (g). d, $\mathbf{h}$ The same as $\mathbf{c}$ and $\mathbf{g}$ but for changes in EXP2030. All differences have been calculated using years $21-100$ of the simulations particularly in the Labrador Sea, and consequently on the global ocean circulation (Jungclaus et al. 2005; Holland et al. 2001). Observationally based estimates suggested exports of about 0.7-1 Sv (Vinje et al. 1998, Kwok and Rothrock 1999, Schmith and Hansen 2003), which fits well to the simulated values of EC-Earth: in EXP2000, the ice export through Fram Strait reaches about $0.8 \mathrm{~Sv}$ in average, $0.7 \mathrm{~Sv}$ in EXP2015 and drops below $0.5 \mathrm{~Sv}$ in the last 30 years of EXP2030 (Fig. 6e, f). This reduced ice export in EXP2030 goes along with a thinning of the ice (not shown), which overcomes a potential increase in velocity, and is in line with future projections (Koenigk et al. 2007, 2013; Vavrus et al. 2012). Together with the drop in the mean ice export, the interannual to decadal variations are strongly decreased in the last 30 years of EXP2030. Figure 7 shows the spatial distribution of sea ice concentration in EXP2000 and the changes in EXP2015 and EXP2030. EXP2000 simulates too much ice in the Greenland Sea, and slightly too little ice along the rest of the ice edges in March compared to the OSISAF satellite data product (Eastwood et al. 2010). Generally, the ice concentration is too high along the ice edges in September. In EXP2015, in March, the ice concentration is mainly decreased in the Barents Sea, north of Iceland and in the Sea of Okhotsk. A slight increase can be seen in the Greenland Sea south of Svalbard in both EXP2015 and EXP2030. This increase might be related to northerly wind anomalies in this area
(Fig. 8a, c). The changes in sea ice concentration strongly affect $\mathrm{Q}_{\mathrm{TLA}}$ with a dipole-like pattern (Fig. 3); the strongest turbulent heat loss to the atmosphere moves northward together with the ice edge in EXP2015 and EXP2030.

In September, sea ice decreases mainly in the Barents Sea and in the Beaufort Sea along the North America coast in EXP2015. In EXP2030, we see a more general retreat of sea ice along all ice edges with largest reductions in the Barents and Kara Seas. Compared to the sea ice change in transient CMIP5 climate projections with EC-Earth 2.3 (Koenigk et al. 2013), the response is somewhat less focused on the Barents Sea region.

\subsection{Changes in the atmosphere}

\subsubsection{Atmospheric circulation}

Observations and recent studies suggested substantial changes in the large scale atmospheric circulation and linked these changes to the recent observed Arctic sea ice reduction (a review is given in Vihma 2014). Our simulations indicate, despite the strong changes in $\mathrm{Q}_{\mathrm{TLA}}$ (Fig. 3), no dramatically changing atmospheric circulation between the three climate states (Fig. 8, left). Still, some areas with a significant SLP response occur in EXP2015 and EXP2030 compared to EXP2000. In winter, significantly increased SLP is found over the North Pacific and southern 
Fig. 8 Difference in SLP (left) and T2m (right) between EXP2015 and EXP2000 in winter $(\mathbf{a}, \mathbf{b})$ and in summer (e, f) and between EXP2030 and EXP2000 in winter $(\mathbf{c}, \mathbf{d})$ and summer $(\mathbf{g}, \mathbf{h})$. Average over years $21-100$ of the simulations. For SLP, black lines indicate a significance level of $95 \%$. For T2m, only areas exceeding the $95 \%$ significance level are shown
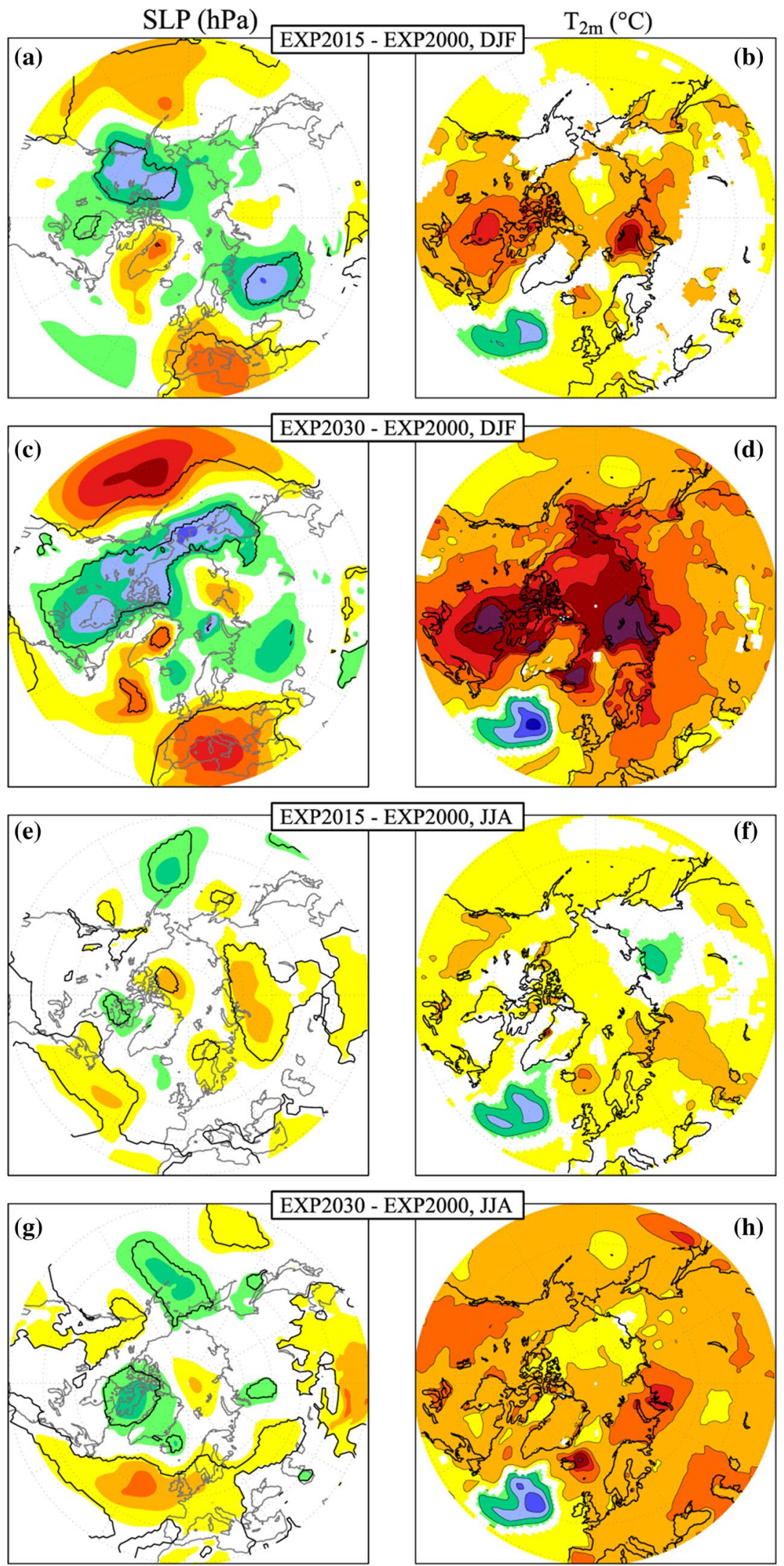

$-2 \quad-1.6-1.2-0.8-0.5-0.20 .20 .50 .81 .2 \quad 1.6 \quad 2$ 
Fig. 9 Winter (DJF) SLP $(\mathbf{a}, \mathbf{b})$ and $\mathrm{T} 2 \mathrm{~m}(\mathbf{c}, \mathbf{d})$ differences between EXP2015 and EXP2000 (a, c) and between EXP2030 and EXP2000 (b, d) for selected 30-year periods of the simulations (years 32-61 in a and $\mathbf{c}$; years $47-76$ in $\mathbf{b}$ and $\mathbf{d})$ (a) SLP, EXP2015 - EXP2000

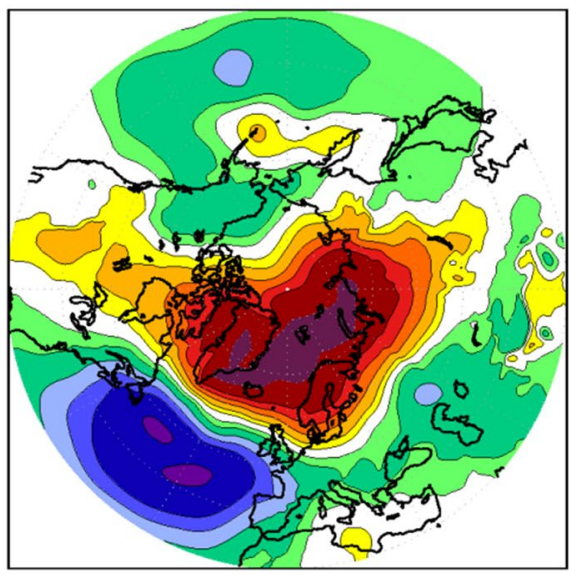

(c) $\mathrm{T} 2 \mathrm{~m}, \mathrm{EXP} 2015$ - EXP2000
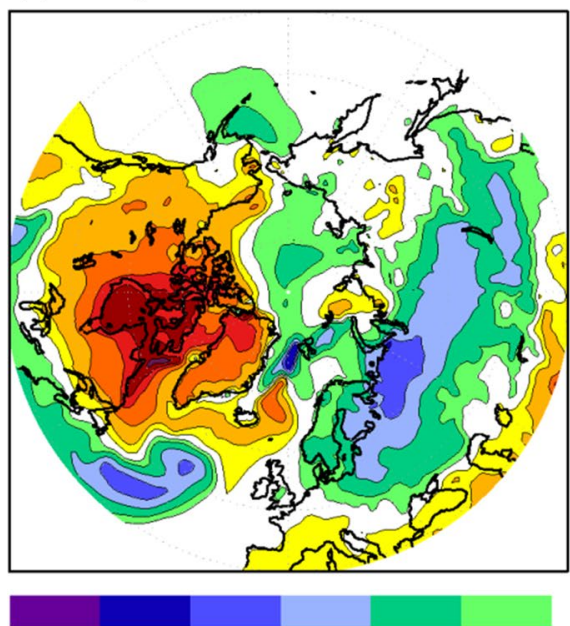

(b) SLP, EXP2030 - EXP2000

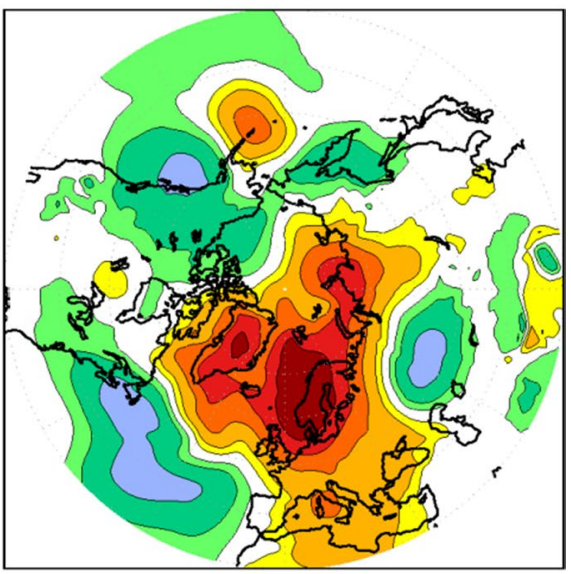

(d) T2m, EXP2030 - EXP2000
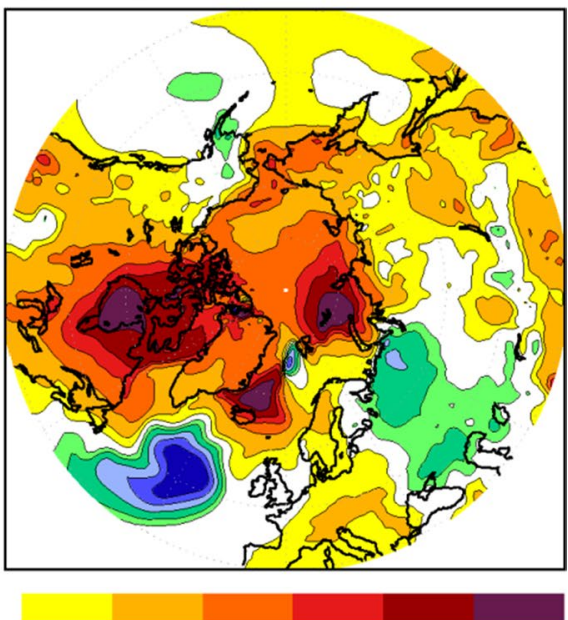

$\mathrm{hPa} /{ }^{\circ} \mathrm{C}$

Europe, and reduced SLP from northern Canada towards eastern Siberia. The response pattern is similar in EXP2015 and EXP2030 but the amplitude of the response is larger in EXP2030. Over the North Pacific, the change pattern in winter agrees with the observed positive trend in the last decades. In contrast to this, the simulated SLP-changes over the North Atlantic-Eurasian area do not agree with the observed trend pattern, which is dominated by positive SLP trends extending from the Nordic Seas across large parts of northern Asia, and negative trends over the North Atlantic. Our results agree largely with results by Barnes and Polvani (2015) who found that the projected response of the circulation in CMIP5 models is either in the opposite direction to the observed one, or the spread among the models is too large to discern any robust response. It is unclear if the CMIP5 models are not able to reproduce the observed trends or if the observed trends are not robust. Most recent studies analyzing the linkage between sea ice reduction and atmospheric circulation trends were based on observational data of a time length of roughly 30 years. In order to investigate the robustness of the atmospheric changes between EXP2030, EXP2015 and EXP2000 for 30 -year periods, our three 100-year simulations are subsampled into different 30-year periods. To keep it simple, we use 30-year running mean differences of SLP and T2m. Interestingly, it turns out that the SLP-differences between EXP2000, EXP2015 and EXP2030 vary strongly between 30 -year periods; we find both positive and negative NAOlike atmospheric responses to 2015 and 2030 greenhouse gas concentrations in different 30 -year periods. Figure 9 shows an example of possible SLP and T2m differences between EXP2015 and EXP2000 and EXP2030 and EXP2000 in winter. Especially, the EXP2015-EXP2000 difference is dominated by a strong negative NAO pattern (Fig. 9a). This leads to a cooling over a large area from northern and eastern Europe across Asia, with a maximum temperature decline of almost $2 \mathrm{~K}$. This cooling is of similar amplitude as the observed one in the last decades 
(a) EXP2000, EOF1, $31.5 \%$

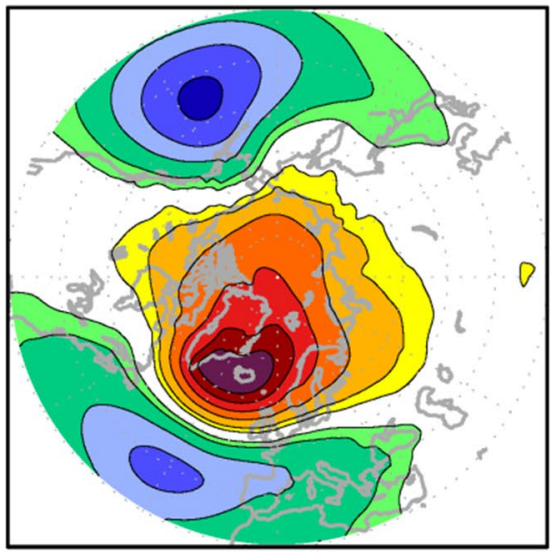

(d) EXP2000, EOF2, $14.9 \%$ (b) EXP2015, EOF1, $35.7 \%$

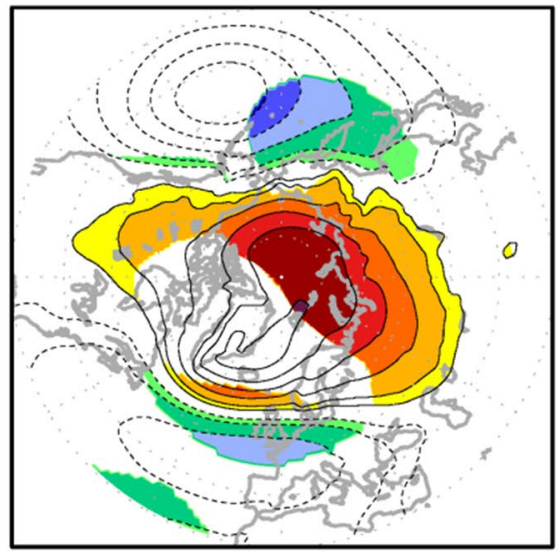

(e) EXP2015, EOF2, $21.4 \%$

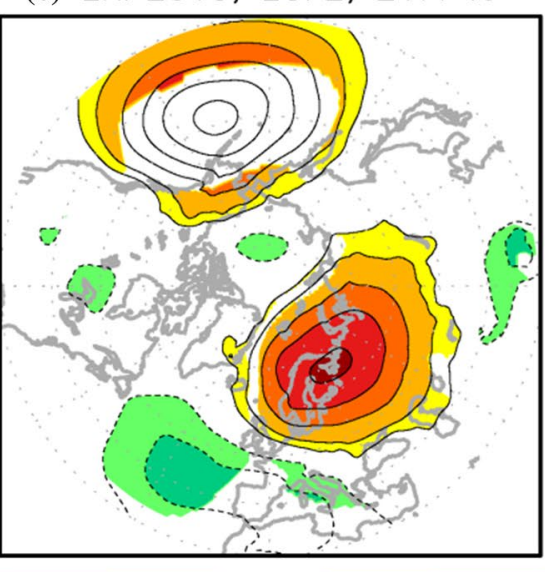

(c) EXP2030, EOF1, $30.9 \%$

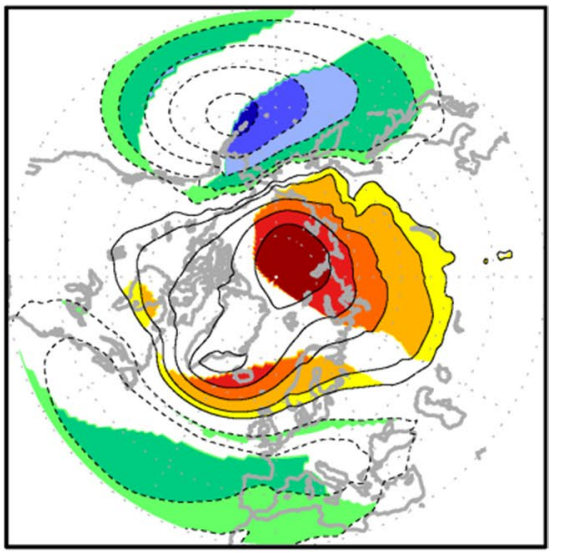

(f) EXP2030, EOF2, $19.9 \%$

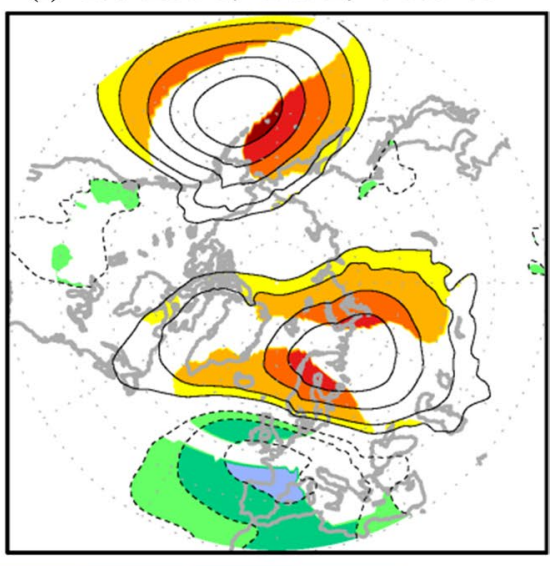

$\begin{array}{llllll}-5 & -4 & -3 & -2 & -1 & -0.5\end{array}$

$\mathrm{hPa}$

Fig. 10 First $(\mathbf{a}-\mathbf{c})$ and second EOF (d-f) of SLP in winter (DJF) using $30^{\circ}-90^{\circ} \mathrm{N}$ and years $21-100$ in EXP2000 (a, d), EXP2015 (b, e) and EXP2030 (c, f). In b, c, e, f, colored areas indicate sig- nificant (exceeding the $95 \%$ level) differences between the EOFs in EXP2015 (EXP2030) and EXP2000

are needed to see robust atmospheric circulation changes in response to sea ice loss.

In summer, the SLP response to enhanced greenhouse gas forcing in EXP2015 and EXP2030 is generally relatively weak (below $1 \mathrm{hPa}$ almost everywhere), although quite large areas with significant changes of SLP can be seen: increased SLP occurs over the North Atlantic, parts of Europe and Asia, and decreased SLP occurs west of Greenland and over the North Pacific (Fig. 8e, g).

To investigate possible changes in the variability of the winter atmospheric circulation in EXP2015 and EXP2030 compared to EXP2000, we calculated Empirical Orthogonal Functions (EOF) of the winter (DJF) averaged SLP between $30^{\circ} \mathrm{N}$ and $90^{\circ} \mathrm{N}$ (Fig. 10). The first EOF shows a similar large scale pattern representing the Arctic. Oscillation and explaining roughly $30 \%$ of the total variance 
in all three simulations. However, we see a weakening of variations in the North Atlantic area, and the area with the strongest signal, around Iceland, extends further to the north in EXP2015 and moves into the Central Arctic in EXP2030. This extension into the Arctic is significant but the change over the Iceland-Nordic Seas area is not significant. Also the centre of action over the North Pacific moves slightly northward, which leads to a substantial increase of the SLP-gradient in the area of the Bering Strait.

The second EOF, which explains $15 \%$ of the variance in EXP2000 and about $20 \%$ in EXP2015 and EXP2030, shows a large signal over the northern North Pacific in all three simulations. However, it differs distinctly and significantly over the North Atlantic-European area: while EXP2000 has poles south of Iceland and over southwestern Europe, EXP2015 and EXP2030 both show a dipole with a large signal over northeastern Europe/Barents Sea region and southwestern Europe. This Barents Sea-southwestern Europe pattern can be found in EOF4 of EXP2000 but its importance is obviously growing in EXP2015 and EXP2030. Such a pattern favors northerly and easterly wind anomalies and thus cold winter conditions over parts of Asia and Eastern Europe, and resembles the observed atmospheric pattern in the cold winter 2010/2011.

\subsubsection{Air temperature}

The winter $2 \mathrm{~m}$ air temperature (Fig. 8, right) is already in EXP2015 significantly increased in most mid and high latitude regions compared to EXP2000. A region with a significant reduction of $\mathrm{T} 2 \mathrm{~m}$ occurs over the North Atlantic, which is related to the cooling in ocean surface temperature (Fig. 2) and to the reduced $\mathrm{Q}_{\mathrm{TLA}}$ into the atmosphere (Fig. 3). The amplitude and extension of this cooling area is somewhat smaller for T2m compared to SST. This can be explained by the limited size of the Atlantic cold blob and the advection of warmer air masses from the surrounding areas with warmer SST. No significant T2m change occurs in an area extending from eastern Europe towards central Asia in EXP2015. The largest warming takes place over the Barents Sea with up to $3 \mathrm{~K}$, otherwise the warming stays below $1.5 \mathrm{~K}$ over the continents and does not exceed $0.5 \mathrm{~K}$ over the ocean. In EXP2030, the warming in winter is strongly intensified and reaches more than $2 \mathrm{~K}$ in the entire Arctic (up to $5 \mathrm{~K}$ in the Barents Sea and Hudson Bay) and 1-2 K over the mid and high-latitude continents. Over the North Atlantic, instead, the cooling further amplifies and reaches -1 to $-2 \mathrm{~K}$ southeast of Greenland. The strong warming in the Barents Sea is a consequence of the retreat of sea ice and enhanced surface heat fluxes. In the Hudson Bay, the sea ice concentration does not change but the ocean heat loss to the atmosphere increases. This might be due to reduced ice thickness in winter (not shown).
Furthermore, the SLP-changes (Fig. 8a, c) indicate anomalous southerly winds that advect warmer air masses into the Hudson Bay area.

In summer, the warming is more evenly distributed with about 0-1 K in EXP2015 and 0.5-1.5 K in EXP2030. Again, a significant cooling occurs over the North Atlantic south of Greenland.

In winter, the vertical temperature distribution in the Arctic atmosphere is characterized by a strong near-surface inversion in the high Arctic in EXP2000 (Fig. 11). Warmest temperatures are typically found in heights between 850 and $900 \mathrm{hPa}$. At the surface, the temperature is up to $6 \mathrm{~K}$ colder, because of the continuous loss of heat from the surface through emission of infrared radiation. In addition, the insulating properties of the sea ice and snow prevent the heat exchange between the relatively warm ocean beneath the ice and the cold atmosphere. The strength and the spatial pattern of the inversion in EXP2000 (not shown) agree well with results based on the ERA-interim reanalysis data (Medeiros et al. 2011).

In EXP2015 and EXP2030, the strongest warming signal occurs near the surface, which tends to reduce the winter inversion strength and thus the atmospheric stability in the Arctic. Compared to lower latitudes, the temperature amplification decreases with height and disappears above $800 \mathrm{hPa}$ in EXP2015. In EXP2030, the amplification extends far more up (up to $500 \mathrm{hPa}$ ) and is largest near the pole, while in EXP2015 it is more constrained to $70-85^{\circ} \mathrm{N}$.

In summer, the Arctic atmosphere is relatively uniformly warmed with $0-1 \mathrm{~K}$ in EXP2015 and up to $1.5 \mathrm{~K}$ in EXP2030 (not shown).

The zonal mean distribution of the specific humidity follows closely the temperature distribution in EXP2000 (Fig. 11d). The changes in EXP2015 and EXP2030 show a much stronger increase of specific humidity at the surface at all latitudes, but contrarily to temperature, no amplification at high latitudes. The reason for this is the exponentially growing capacity of warmer air to uptake water vapor.

\subsection{Arctic-mid latitude linkages}

A number of studies suggested a possible link between the observed sea ice reduction and the large scale atmospheric circulation and mid-latitude air temperature (Jaiser et al. 2013; Inoue et al. 2012; Petoukhov and Semenov 2010; Hopsch et al. 2012; Overland et al. 2011; Peings and Magnusdottir 2014; Rinke et al. 2013; Koenigk et al. 2016). Most of these studies used either the difference between the last decade (with little ice) and the previous two (with much ice), or they used detrended time series to assess the atmospheric response to sea ice variability and trend. One common problem for all these studies is the fact that 


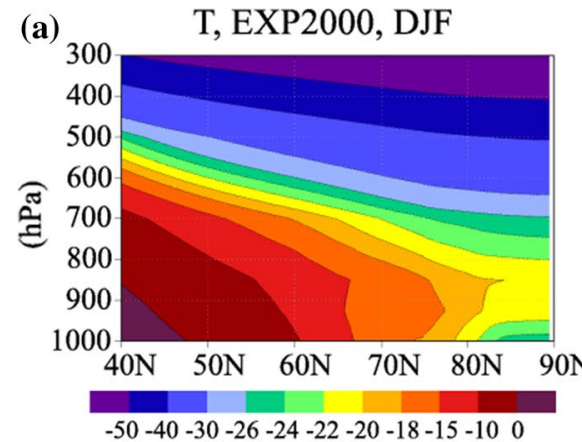

$\left({ }^{\circ} \mathrm{C}\right)$

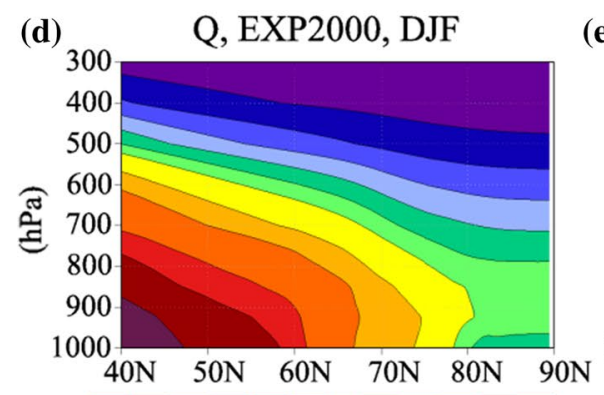

0.10 .20 .30 .40 .50 .60 .81 .01 .52 .03 .0 $(\mathrm{g} / \mathrm{kg})$

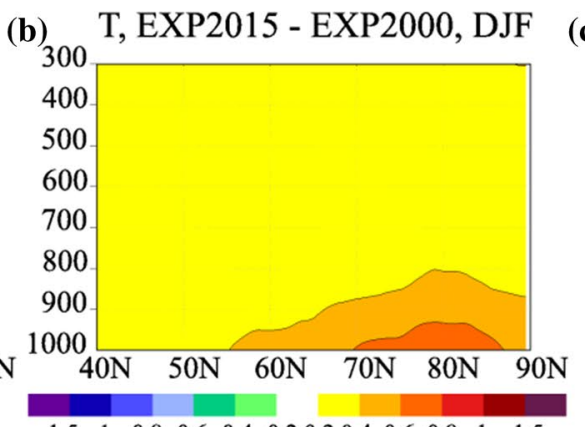

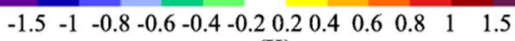

(K)

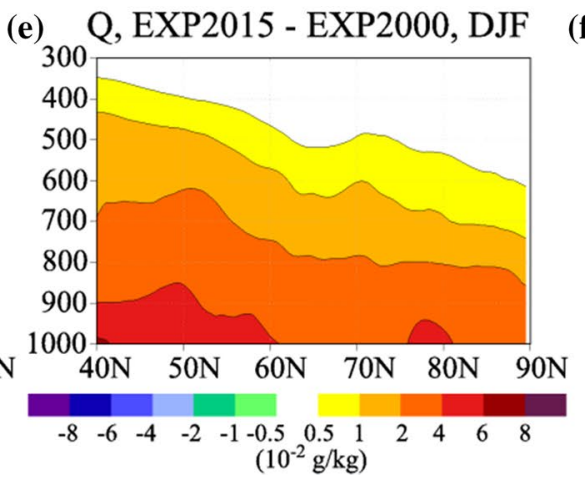

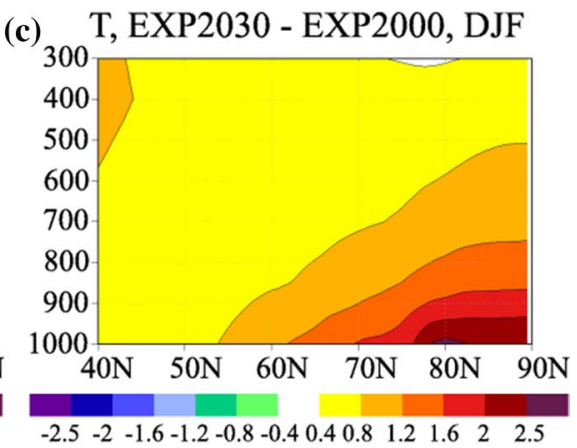

(K)

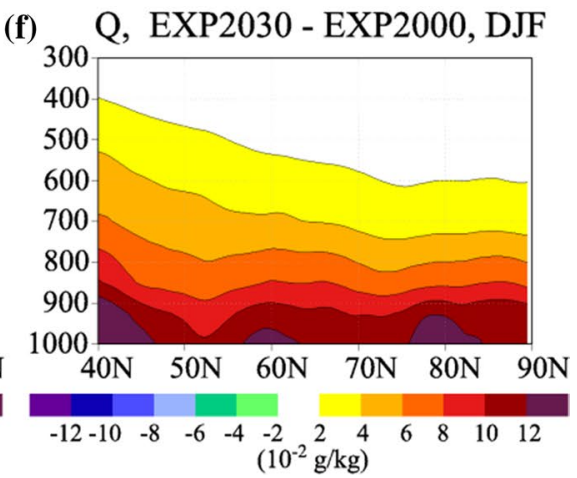

Fig. 11 Zonal mean average of air temperature (T) in EXP2000 in winter (DJF, a) and change in EXP2015 (b) and EXP2030 (c). d-f The same as a-c but for specific humidity (Q). Shown is the aver-

observational time series are very short. Moreover, they are derived from a climate in transition, which means that both external and internal forcing have likely changed during the three decades of observations.

Here, we investigate the relationship between sea ice anomalies in autumn and SLP and T2m in the following winter, in our three quasi equilibrium simulations, using correlation analysis. This analysis is performed based on variations of sea ice area in eight different Arctic regions as defined in Koenigk et al. (2016) (Northern Hemisphere, Barents-Kara Seas, Greenland Sea, Labrador Sea-Baffin Bay, Laptev-East Siberian Seas, Chukchi-Bering Seas, Beaufort Sea, Central Arctic). The general result is that the correlation between autumn sea ice and winter SLP is weak in all three simulations, and that air temperature shows the strongest response in the location of the ice anomaly and its surroundings. In the following, we will therefore only shortly discuss the response to November ice anomalies in the Barents and Kara Seas area (BAKA, Fig. 12) since previous studies found that the atmospheric response is largest to November sea ice anomalies in the BAKA region. The correlation between November ice area in the BAKA region and SLP in the following winter is below 0.3 everywhere in EXP2000. A small local response in the Kara Sea region can be seen, which is significant at the $95 \%$ level. The T2m age over years $21-100$ of the simulations. Note that the scale differs between $\mathbf{b}$ and $\mathbf{c}$ and between $\mathbf{e}$ and $\mathbf{f}$

response in EXP2000 shows somewhat higher correlations: a significantly negative correlation from the Nordic Seas across the BAKA area (here correlation is maximal and exceeds -0.6) and Siberia to the North Pacific. This means that less ice in the BAKA area leads to a warming. The explanation for this local response is relatively simple: little sea ice in November in the BAKA area leads to reduced sea ice extent in winter-due to the persistence of the ice anomaly - and consequently to warmer temperatures in the Barents Sea. Significantly negative T2m anomalies occur also over southern North America, and positive anomalies over the western North Pacific. These anomalies seem to be related to SLP anomalies, which are not significant but have the potential to advect cold and warm air masses in the regions of the $\mathrm{T} 2 \mathrm{~m}$ anomalies. Very small positive correlations can also be seen over Central Asia.

In EXP2015, the correlation between November ice and winter SLP is still weak, although some slightly larger areas with significant correlations are found over eastern Siberia and central Europe. The strongest negative correlations between ice and $\mathrm{T} 2 \mathrm{~m}$ occur in the Barents Sea and its surroundings. Furthermore, we see more wide-spread negative correlations extending from Florida across the North Atlantic towards southern Europe, and negative correlations over the northeastern North Pacific. In EXP2030, the 


\section{SLP correlation}

(a) SLP, DJF, EXP2000

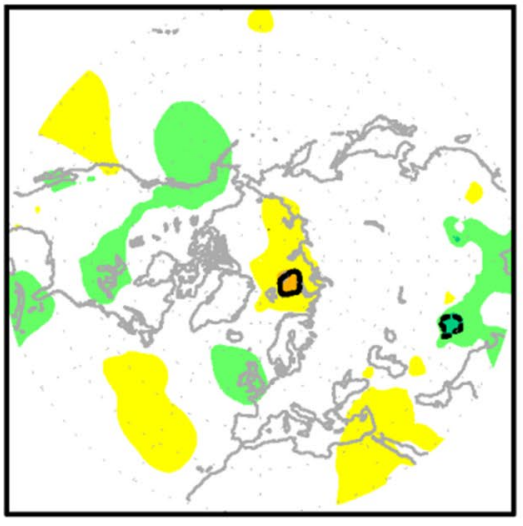

(d) T2m, DJF, EXP2000

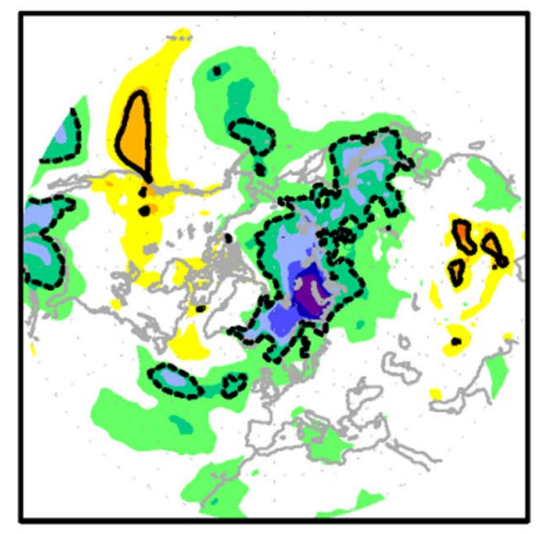

(b) SLP, DJF, EXP2015

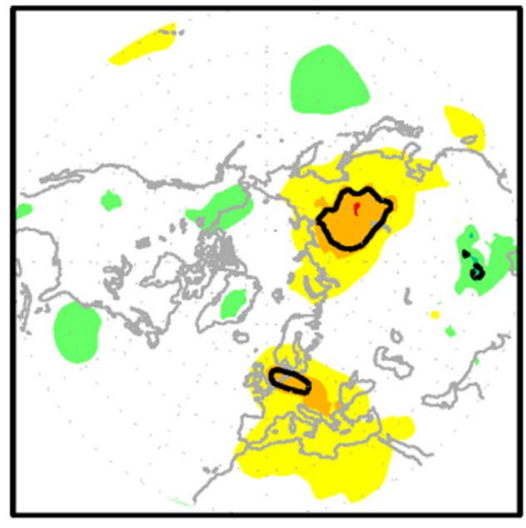

$\mathrm{T} 2 \mathrm{~m}$ correlation

(e) T2m, DJF, EXP2015

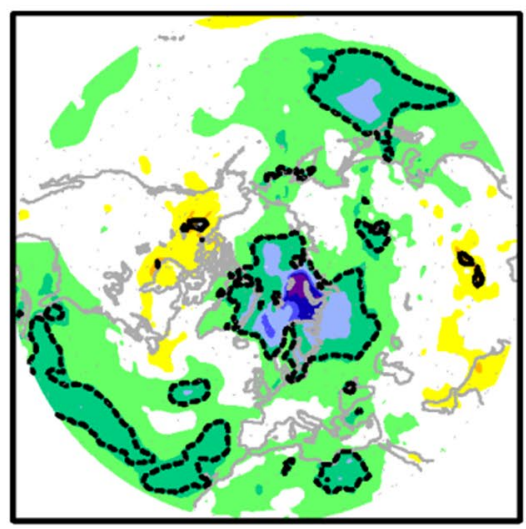

(c) SLP, DJF, EXP2030

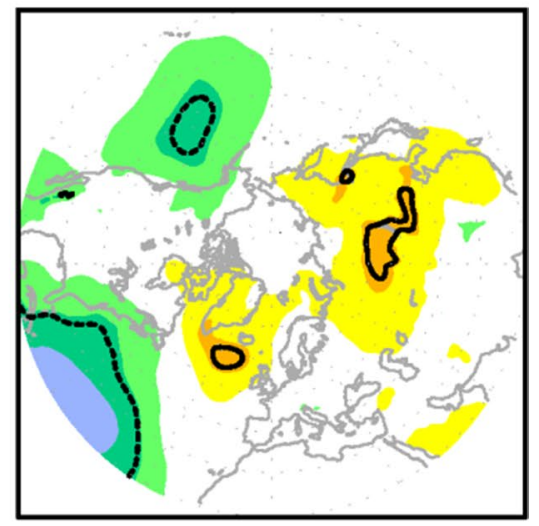

(f) $\mathrm{T} 2 \mathrm{~m}, \mathrm{DJF}, \mathrm{EXP} 2030$

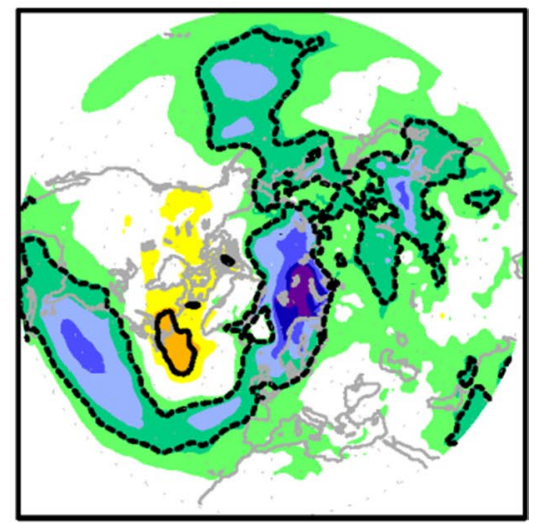

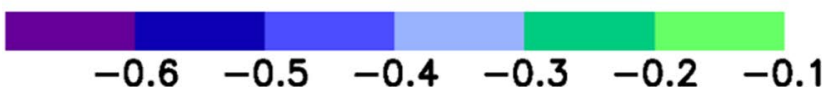

$\begin{array}{llllll}-0.6 & -0.5 & -0.4 & -0.3 & -0.2 & -0.1\end{array}$

Fig. 12 Correlation between sea ice area in the Barents-Kara Seas $\left(70^{\circ}-82^{\circ} \mathrm{N}, 15^{\circ}-100^{\circ} \mathrm{E}\right)$ in November and SLP $(\mathbf{a}-\mathbf{c})$ in the following winter (DJF) in EXP2000 (a), EXP2015 (b) and EXP2030 (c). d-f

SLP response is similar as in EXP2015 over eastern Asia, but in addition, a significantly negative correlation occurs over the subtropical North Atlantic and over the western North Pacific. Significantly negative temperature correlations extend now all the way from the Caribbean across the North Atlantic, following the North Atlantic Current into the Arctic and further into the North Pacific and eastern Asia. Over a small area of the North Atlantic that spreads from eastern Canada to the south of Greenland, a positive correlation is found.

We performed the same correlation analysis with detrended data (not shown). The results are generally similar to the results from the analysis using the raw data.

\section{$\begin{array}{llllll}0.1 & 0.2 & 0.3 & 0.4 & 0.5 & 0.6\end{array}$}

The same as $\mathbf{a}-\mathbf{c}$ but for correlation between Barents-Kara Seas sea ice area and $2 \mathrm{~m}$ air temperature. Black lines indicate a significance level of $95 \%$

However, significantly positive correlations between sea ice and $\mathrm{T} 2 \mathrm{~m}$ occur over the North Atlantic subpolar gyre (up to $r=0.32$ ) and weaker negative correlations along the North Atlantic Current compared to the correlations of the raw data.

None of our three simulations reproduces the suggested relation between reduced sea ice in the Barents Sea area and a trend towards more negative NAO winter atmospheric conditions. However, if we, instead of using the entire 80-year period, perform the same correlation analysis for different 30 -year periods, we find large variations in the relation between sea ice and SLP (Fig. 13). Note, that correlations exceeding $\mp 0.38$ are significant at 
Fig. 13 Correlation between sea ice area in the Barents-Kara Seas $\left(70^{\circ}-82^{\circ} \mathrm{N}, 15^{\circ}-100^{\circ} \mathrm{E}\right)$ in November and SLP in the following winter (DJF) in EXP2000 (a, b) and EXP2030 $(\mathbf{c}, \mathbf{d})$. Correlations are shown for two selected 30-year time periods: years 40-69 (a, c) and years 70-99 (b, d)

\section{SLP correlation}

(a) EXP2000, year 40-69

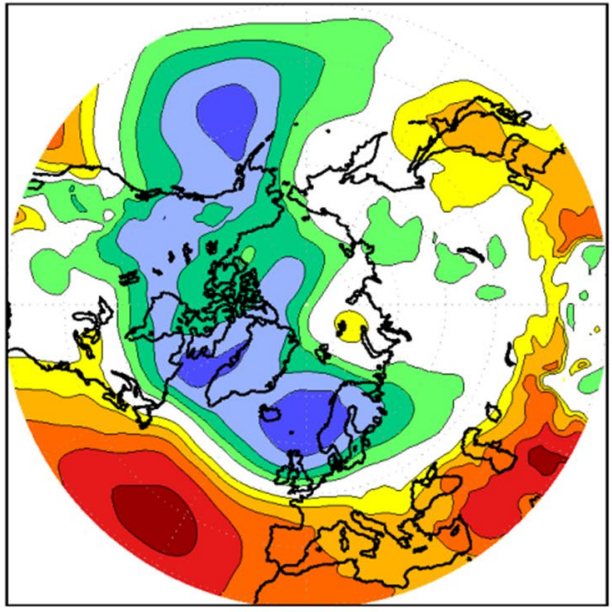

(c) EXP2030, year 40-69

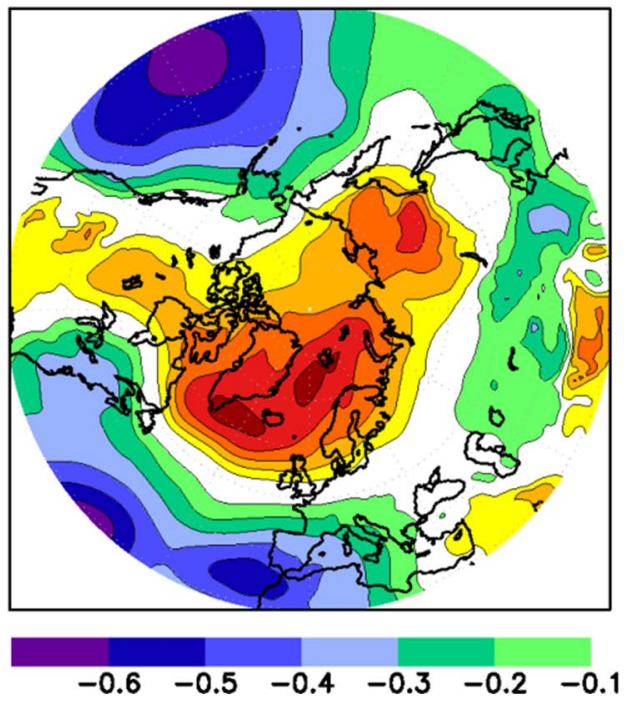

(b) EXP2000, year 70-99

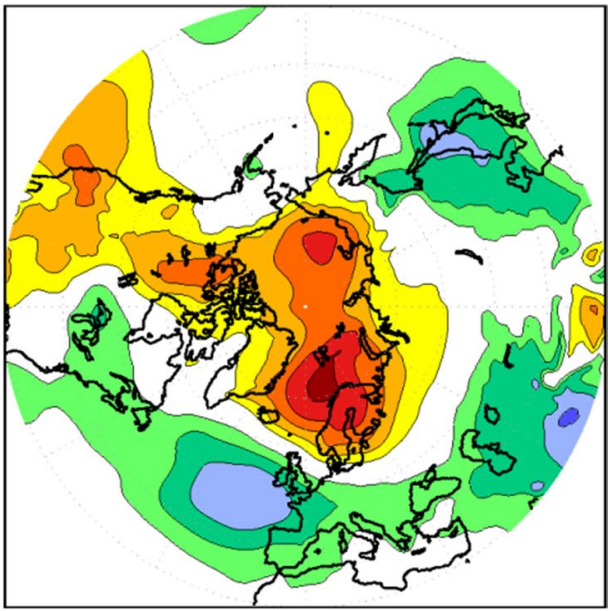

(d) EXP2030, year 70-99

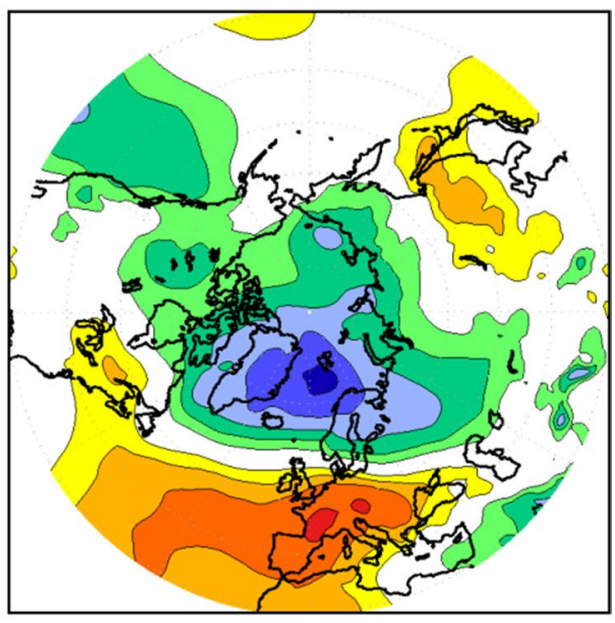

$\begin{array}{llllll}0.1 & 0.2 & 0.3 & 0.4 & 0.5 & 0.6\end{array}$ the $95 \%$ significance level, based on a two-sided $t$ test and assuming 30 degrees of freedom and a normal distribution. For EXP2000 and EXP2030, 30-year periods exist with a NAO-like response pattern to reduced sea ice area in the BAKA area in November. The correlation coefficients reach similar amplitudes as the observed correlations (compare Koenigk et al. 2016, Fig. 4). Thus, EC-Earth is able to simulate a SLP response, which is similar to the observed response. Interestingly, neighboring 30-year periods show a NAO + like response of the winter SLP to ice reductions in the BAKA area. This shows that the response in our model is not robust over time and it indicates that 30 -year periods are very short to make robust statements about a possible relationship between sea ice variations and mid-latitude climate variations.

\section{Summary and conclusions}

Different states of Arctic climate have been analyzed in three quasi-equilibrium simulations with the global coupled model EC-Earth. Each of these simulations was forced by a constant greenhouse gas forcing, corresponding to years 2000, 2015 and 2030, with the latter two based on the RCP4.5 emission scenario. The Arctic temperature shows an amplified warming under 2030-level greenhouse gas forcing compared to the warming under year-2015 forcing. This goes along with an accelerated reduction of the Arctic sea ice extent between EXP2030 and EXP2015 compared to the reduction between EXP2015 and EXP2000. Both Arctic warming and sea ice reduction are closely linked to the increase of ocean heat flux into the Arctic, particularly through the Barents Sea Opening. In contrast to the ice 
extent, the Arctic ice volume is reduced more linearly. This indicates that an initial thinning of sea ice towards a critical value is needed before ice concentration can substantially be reduced. Given the fact that EC-Earth3.0.1 has a cold bias of roughly one degree Celsius in the Arctic and slightly overestimates the ice extent and volume in EXP2000, it is possible that the real-world has already reached such a critical ice thickness and is already in the state of accelerated sea ice extent reduction. Our model simulations might therefore be more representative for changes in the recent past than for upcoming future changes.

Decadal variations of Arctic sea ice extent and ice volume are large in all three simulations. These variations are dominated by the variability of the ocean heat transports into the Arctic through the Barents Sea Opening and the Bering Strait. The simulated variations of ice extent reach about two-thirds of the observed ice extent reductions during the last 30 years. This underlines the difficulty to extract the trend (caused by increased greenhouse gas forcing) from the observed sea ice reduction signal, and thus to make clear statements on the ability of global climate models to simulate the observed sea ice trend.

Despite a general warming of mid and high northern latitudes under present day and near future forcing compared to the recent past greenhouse gas forcing, a substantial cooling occurs in the subpolar gyre of the North Atlantic. This cooling agrees well with the recently debated and observed Atlantic cold blob. It is likely related to strong reductions in the AMOC and the associated weaker northward oceanic heat transports in EXP2030 and EXP2015 compared to EXP2000. In EXP2030, the AMOC is reduced by about $3 \mathrm{~Sv}$, which is almost three times as large as the AMOC reduction between year 2030 and year 2000 in transient climate simulations with the CMIP5 model version of EC-Earth. The weakening of the AMOC in our simulations is mainly caused by reduced deep water formation in the Labrador Sea. Since the AMOC is highly positively correlated with the Arctic temperature in all three simulations, the reduction of the AMOC might have a dampening effect on the Arctic temperature increase in EXP2015 and EXP2030. AMOC differences between our simulations decrease towards the end of the simulations. It remains unclear if this is only due to variations or if the AMOC is partly recovering in EXP2015 and EXP2030. In the latter case, also the cold blob in the North Atlantic would likely become less pronounced.

After year 60, EXP2030 experiences a temperature increase in the Arctic. This is related to a resurgence of deep-water convection in the Labrador Sea-after a shutdown of 40 years-and an associated increase of the AMOC and the northward heat transport through the Barents Sea into the Arctic. As a consequence of this warming, Arctic sea ice extent, volume and export through the
Fram Strait are decreased. It remains unclear if this warming period is a late response to the changes in greenhouse gas forcing or if it is caused by natural climate variations.

The vertical temperature change in winter in EXP2015 and EXP2030 compared to EXP2000 is dominated by a near surface amplification in high northern latitudes. While the warming is largest at about $78^{\circ} \mathrm{N}$ and near the surface in EXP2015, EXP2030 shows a stronger temperature amplification in all Arctic latitudes, which extends vertically up to $500 \mathrm{hPa}$ height.

The simulated responses to 2015 and 2030-greenhouse gas forcing do not reproduce any of the much debated observed trend patterns, such as the trend towards a more negative NAO-index or the cooling trend over parts of Eastern Europe and Asia if using the last 80 years of our simulations. However, when comparing selected 30-year periods, both negative and positive NAO-like changes, which are of similar amplitude as the observed trends over the last 30 years, are found. This indicates that either our model is not fully able to reproduce the observed relationship between sea ice reduction and NAO, or the observed trends might not be robust over longer time periods. The observed trends might at least partly be caused by natural variations.

Furthermore, we do not find any clear impact of Arctic ice variations on remote regions in mid and high latitudes when considering the entire length of the simulations; we mainly find a local response in the area of the ice anomaly. This local response increases from recent past to near future. However, for shorter time periods, large variations in the response of the large-scale atmospheric circulation to sea ice variations occur. We find 30-year periods with both $\mathrm{NAO}+$ and NAO-like responses to Arctic sea ice reductions. First, this shows that EC-Earth is generally able to reproduce the observed atmospheric response to sea ice variations. Second, it indicates the possibility that this relation might not be robust over time in the real world either. Internal climate variability is too large to allow final conclusions from 30 years of observations.

Acknowledgments This study has been made possible by support of the Rossby Centre at the Swedish Meteorological and Hydrological Institute (SMHI) and the Bolin Centre for Climate Research together with the NORDFORSK Top Level research Initiative, Project No. 61841-GREENICE. The computations were performed on resources provided by the Swedish National Infrastructure for Computing (SNIC) at the National Supercomputer Centre at Linköping University (NSC).

Open Access This article is distributed under the terms of the Creative Commons Attribution 4.0 International License (http://creativecommons.org/licenses/by/4.0/), which permits unrestricted use, distribution, and reproduction in any medium, provided you give appropriate credit to the original author(s) and the source, provide a link to the Creative Commons license, and indicate if changes were made. 


\section{References}

Stocker T et al (2013) Climate Change 2013: The Physical Science Basis. Contribution of Working Group I to the Fifth Assessment Report of the Intergovernmental Panel on Climate Change. Cambridge University Press, Cambridge, United Kingdom and New York, NY, USA

Alexander M, Bhatt U, Walsh J, Timlin M, Miller J, Scott J (2004) The atmospheric response to realistic Arctic sea ice anomalies in an AGCM during winter. J Clim 17:890-905

Barnes EA (2013) Revisiting the evidence linking Arctic amplification to extreme weather in midlatitudes. Geophys Res Lett 40:4734-4739. doi:10.1002/grl.50880

Barnes EA, Polvani LM (2015) CMIP5 projections of arctic amplification, of the North American/North Atlantic circulation, and of their relationship. J Clim 28:5254-5271. doi:10.1175/ JCLI-D-14-00589.1

Barnes EA, Screen JA (2015) The impact of Arctic warming on the midlatitude jet-stream: Can it? Has it? Will it? WIREs Clim Change 6:277-286. doi:10.1002/wcc.337

Batté L, Doblas-Reyes FJ (2015) Stochastic atmospheric perturbations in the EC-Earth3 global coupled model: impact of SPPT on seasonal forecast quality. Clim Dyn. doi:10.1007/ s00382-015-2548-7

Belkin I, Levitus S, Antonov J, Malmberg SA (1998) "Great Salinity Anomalies" in the North Atlantic. Prog Oceanogr 41:1-68

Bintanja R, Graversen RG, Hazeleger W (2011) Arctic winter warming amplified by the thermal inversion and consequent low infrared cooling to space. Nat Geosci Lett. doi:10.1038/NGEO1285

Blackport R, Kushner PJ (2016) The transient and equilibrium climate response to rapid summertime sea ice loss in CCSM4. J Clim 29:401-417. doi:10.1175/JCLI-D-15-0284.1

Brodeau L, Koenigk T (2015) Extinction of the northern oceanic deep convection in an ensemble of climate model simulations of the 20th and 21st centuries. Clim Dyn. doi:10.1007/ s00382-015-2736-5

Brown RD, Robinson DA (2011) Northern Hemisphere spring snow cover variability and change over 1922-2010 including an assessment of uncertainty. Cryosphere 5:219-229. doi:10.5194/ tc-5-219-2011

Cavalieri D, Parkinson C, Gloersen P, Zwally HJ (1996) Sea ice concentrations from Nimbus-7 SMMR and DMSP SSM/I-SSMIS passive Microwave Data (NSIDC- 0051). Boulder, Colorado USA: NASA DAAC at the National Snow and Ice Data Center (updated yearly)

Cohen JL, Furtado JC, Barlow MA, Alexeev VA, Cherry JE (2012) Arctic warming, increasing snow cover and widespread boreal winter cooling. Environ Res Lett. doi:10.1088/1748-9326/7/1/014007

Comiso JC, Parkinson C, Gersten R, Stock L (2008) Accelerated decline in the Arctic sea ice cover. Geophys Res Lett. doi:10.102 9/2007GL031972

Davini P, von Hardenberg J, Filippi L, Provenzale A (2015) Impact of Greenland orography on the Atlantic Meridional Overturning Circulation. Geophys Res Lett 42:871-879. doi:10.1002/20 14GL062668

Devasthale A, Sedlar J, Koenigk T, Fetzer EJ (2013) The thermodynamic state of the Arctic atmosphere observed by AIRS: comparisons during the record minimum sea ice extents of 2007 and 2012. Atmos Chem Phys 13:7441-7450. doi:10.5194/ acp-13-7441-2013

Dickson R, Meincke J, Malmberg SA (1988) The "Great Salinity Anomaly" in the northern North Atlantic, 1968-1982. Prog Oceanogr 20:103-151

Döscher R, Wyser K, Meier HEM, Qian M, Redler R (2010) Quantifying Arctic contributions to climate predictability in a regional coupled ocean-ice-atmosphere model. Clim Dyn. doi:10.1007/ s00382-009-0567-y

Eastwood S, Larsen KR, Lavergne T, Nielsen E, Tonboe R. (2010) Global sea ice concentration reprocessing: product user manual, Product OSI-409, Version, 1.3

Eden C, Greatbatch RJ, Böning CW (2004) Adiabatically correcting an eddy-permitting model using large-scale hydrographic data: application to the Gulf Stream and the North Atlantic Current. J Phys Oceanogr 34(4):701-719. doi:10.1175/1520-0485(2004)034<0701:ACAEMU>2.0.CO;2

Francis JA, Vavrus SJ (2012) Evidence linking Arctic amplification to extreme weather in mid-latitudes. Geophys Res Lett. doi:10.102 9/2012GL051000

Francis JA, Chan W, Leathers DJ, Miller JR, Veron DE (2009) Winter Northern Hemisphere weather patterns remember summer Arctic sea-ice extent. Geophys Res Lett. doi:10.1029/200 9GL037274

Garcia-Serrano J, Frankkignoul C (2014) High predictability of the winter Euro-Atlantic climate from cryospheric variability. Nat Geosci. doi:10.1038/NGEO2118

Giles KA, Laxon SW, Ridout AL, Wingham DJ, Bacon S (2012) Western Arctic Ocean freshwater storage increased by winddriven spin-up of the Beaufort Gyre. Nat Geosci 5:194-197. doi:10.1038/ngeo1379

Goosse H, Holland MM (2005) Mechanisms of decadal arctic climate variability in the community climate system model, version 2 (CCSM2). J Clim 18(17):3552-3570

Graversen RG, Wang M (2009) Polar amplification in a coupled climate model with locked albedo. Clim Dyn 33:629-643. doi:10.1007/s00382-009-0535-6

Graversen RG, Mauritsen T, Tjernström T, Källén E, Svensson G (2008) Vertical structure of recent Arctic warming. Nature. doi:10.1038/nature06502

Gregory JM, Stott PA, Cresswell DJ, Rayner NA, Gordon C, Sexton DMH (2002) Recent and future changes in Arctic sea ice simulated by the HadCM3 AOGCM. Geophys Res Lett. doi:10.1029/ 2001GL014575

Haak H, Jungclaus J, Mikolajewicz U, Latif M (2003) Formation and propagation of great salinity anomalies. Geophys Res Lett 30(9):26/1-26/4

Häkkinen S (1999) A simulation of thermohaline effects of a great salinity anomaly. J Clim 6:1781-1795

Hazeleger W, Severijns C, Semmler T, Stefanescu S, Yang S, Wang X, Wyser K, Baldasano JM, Bintanja R, Bougeault P, Caballero R, Dutra E, Ekman AML, Christensen JH, van den Hurk B, Jimenez P, Jones C, Kållberg P, Koenigk T, MacGrath R, Miranda P, van Noije T, Schmith T, Selten F, Storelvmo T, Sterl A, Tapamo H, Vancoppenolle M, Viterbo P, Willén U (2010) EC-Earth: a seamless earth system prediction approach in action. Bull Am Meteor Soc 91:1357-1363. doi:10.1175/2010BAMS2877.1

Hazeleger W, Wang X, Severijns C, Stefanescu S, Bintanja R, Sterl A, Wyser K, Semmler T, Yang S, van den Hurk B, van Noije T, van der Linden E, van der Wiel K (2012) EC-EarthV2: description and validation of a new seamless Earth system prediction model. Clim Dyn. doi:10.1007/s00382-011-1228-5

Holland MM, Bitz CM, Eby M, Weaver AJ (2001) The role of iceocean interactions in the variability of the North Atlantic thermohaline circulation. J Clim 14:656-675

Holland MM, Bitz CM, Tremblay B (2006) Future abrupt reductions in the summer Arctic sea ice. Geophys Res Lett. doi:10.1029/20 06GL028024

Hopsch S, Cohen J, Dethloff K (2012) Analysis of a link between fall Arctic sea ice concentration and atmospheric patterns in the following winter. Tellus A 64 (18624). doi:10.3402/tellusa. v64i0.18264 
Inoue J, Masatake HE, Koutarou T (2012) The role of barents sea ice in the wintertime cyclone track and emergence of a warm-Arctic cold-Siberian anomaly. J Clim 25(7):2561-2568

Jaiser R, Dethloff K, Handorf D (2013) Stratospheric response to Arctic sea ice retreat and associated planetary wave propagation changes. Tellus A. doi:10.3402/tellusa.v65i0.19375

Jakobson E, Vihma T, Palo T, Jakobson L, Keernik H, Jaagus J (2012) Validation of atmospheric reanalyses over the central Arctic Ocean. Geophys Res Lett. doi:10.1029/2012GL05191

Jungclaus JH, Haak H, Latif M, Mikolajewicz U (2005) Arctic-North Atlantic interactions and multidecadal variability of the meridional overturning circulation. J Clim 18(19):4016-4034

Koenigk T, Brodeau L (2014) Ocean heat transport into the Arctic in the twentieth and twenty-first century in EC-Earth. Clim Dyn 42:3101-3120. doi:10.1007/s00382-013-1821-X

Koenigk T, Mikolajewicz U, Haak H, Jungclaus J (2006) Variability of Fram Strait sea ice export: causes, impacts and feedbacks in a coupled climate model. Clim Dyn 26:17-34. doi:10.1007/ s00382-005-0060-1

Koenigk T, Mikolajewicz U, Haak H, Jungclaus J (2007) Arctic freshwater export in the 20th and 21st century. J Geophys Res. doi:10.1 029/2006JG000274

Koenigk T, Mikolajewicz U, Jungclaus J, Kroll A (2009) Sea ice in the Barents Sea: seasonal to interannual variability and climate feedbacks in a global coupled model. Clim Dyn 32:1119-1138. doi:10.1007/s00382-008-0450-2

Koenigk T, Brodeau L, Graversen RG, Karlsson J, Svensson G, Tjernström M, Willen U, Wyser K (2013) Arctic climate change in 21st century CMIP5 simulations with EC-Earth. Clim Dyn 40:2720-2742. doi:10.1007/s00382-012-1505-y

Koenigk T, Caian M, Nikulin G, Schimanke S (2016) Regional Arctic sea ice variations as predictor for winter climate conditions. Clim Dyn 46:317-337. doi:10.1007/s00382-015-2586-1

Kvamstö NG, Skeie P, Stephenson DB (2004) Large-scale impact of localized Labrador sea-ice changes on the North Atlantic Oscillation. Int J Climatol 24:603-612

Kwok R, Rothrock DA (1999) Variability of Fram Strait ice flux and North Atlantic Oscillation. J Geophys Res 104(C3):5177-5189

Large WG, Danabasoglu G (2006) Attribution and impacts of upperocean biases in CCSM3. J Clim 19:2325-2346

Liptak J, Strong C (2014) The winter atmospheric response to sea ice anomalies in the Barents sea. J Clim 27:914-924. doi:10.1175/ JCLI-D-13-00186.1

Liu Y, Key JR, Wang X (2008) The influence of changes in cloud cover on recent surface temperature trends in the Arctic. J Clim 21:705-715

Madec G (2008) "NEMO ocean engine". Note du Pole de modélisation, Institut Pierre-Simon Laplace (IPSL), France, No 27 ISSN No 1288-1619

Magnusdottir G, Deser C, Saravanan R (2004) The Effects of North Atlantic SST and Sea Ice Anomalies on the Winter Circulation in CCM3. Part I: main Features and Storm Track Characteristics of the Response. J Clim 17(5):857-876

Mahlstein I, Knutti R (2012) September Arctic sea ice predicted to disappear near $2 \mathrm{C}$ global warming above present. J Geophys Res Atmospheres. doi:10.1029/2011JD016709

Medeiros B, Deser C, Tomas RA, Kay J (2011) Arctic inversion strength in climate models. J Clim 24:4733-4740. doi:10.1175/ 2011JCLI3968.1

Mori M, Watanabe M, Shiogama H, Inoue J, Kimoto M (2015) Robust Arctic sea-ice influence on the frequent Eurasian cold winters in past decades. Nat Geosci. doi:10.1038/NGEO2277

Overland JE, Wang M (2010) Large-scale atmospheric circulation changes are associated with the recent loss of Arctic sea ice. Tellus. doi:10.1111/j.1600-0870.2009.00421.x
Overland JE, Wood KR, Wang M (2011) Warm Arctic - cold continents: climate impacts of the newly open Arctic Sea. Polar Res. doi:10.3402/polar.v30i0.15787

Peings Y, Magnusdottir G (2014) Response of the Wintertime Northern hemisphere atmospheric circulation to current and projected arctic sea ice decline: a numerical study with CAM5. J Clim 27:244-264. doi:10.1175/JCLI-D-13-00272.1

Petoukhov V, Semenov VA (2010) A link between reduced BarentsKara sea ice and cold winter extremes over northern continents. J Geophys Res. doi:10.1029/2009JD013568

Pithan F, Mauritsen T (2014) Arctic amplification dominated by temperature feedbacks in contemporary climate models. Nat Geosci. doi:10.1038/NGEO2071

Rahmstorf S, Box JE, Feulner G, Mann ME, Robinson A, Rutherford S, Schaffernicht EJ (2015) Exceptional twentieth-century slowdown in Atlantic Ocean overturning circulation. Nat Clim Change. doi:10.1038/NCLIMATE2554

Richter-Menge J, Jeffries M (2011) The Arctic, in "State of the Climate in 2010". Bull Am Meteor Soc 92(6):S143-S160

Rinke A, Dethloff K, Dorn W, Handorf D, Moore JC (2013) Simulated Arctic atmospheric feedbacks associated with late summer sea ice anomalies. J Geophys Res Atmos 118:7698-7714. doi:10.1002/jgrd.50584

Schlichtholz P (2011) Influence of oceanic heat variability on sea ice anomalies in the Nordic Seas. Geophys Res Lett. doi:10.1029/2 010GL045894

Schmith T, Hansen C (2003) Fram Strait ice export during the 19th and 20th centuries: evidence for multidecadal variations. J Clim 16(16):2782-2791

Screen JA (2014) Arctic amplification decreases temperature variance in northern mid- to high-latitudes. Nat Clim Change 4:577-582. doi:10.1038/NCLIMATE2268

Screen JA, Simmonds I (2010a) Increasing fall-winter energy loss from the Arctic Ocean and its role in Arctic temperature amplification. Geophys Res Lett. doi:10.1029/201 0GL044136

Screen JA, Simmonds I (2010b) The central role of diminishing sea ice in recent Arctic temperature amplification. Nature. doi:10.1038/nature09051

Screen JA, Deser C, Simmonds I, Tomas R (2014) Atmospheric impacts of Arctic sea-ice loss, 1979-2009: separating forced change from atmospheric internal variability. Clim Dyn. doi:10.1007/s00382-013-1830-9

Serreze MC, Barrett AP, Stroeve JC, Kindig DN, Holland MM (2009) The emergence of surface-based Arctic amplification. Cryosphere 3:11-19

Spielhagen RF, Werner K, Aagaard Sörensen S, Zamelczyk K, Kandiano E, Budeus G, Marchitto TM, Hald M (2011) Enhanced modern heat transfer to the arctic by warm Atlantic water. Science 331:450-454. doi:10.1126/science.1197397

Sterl A, Bintanja R, Brodeau L, Gleeson E, Koenigk T, Schmith T, Semmler T, Severijns C, Wyser K, Yang S (2012) A look at the ocean in the EC-Earth climate model. Clim Dyn. doi:10.1007/ s00382-011-1239-2

Swart NC, Fyfe JC, Hawkins E, Kay JE, Jahn A (2015) Influence of internal variability on Arctic sea-ice trends. Nat Clim Change 5:86-89. doi:10.1038/nclimate2483

Tietsche S, Notz D, Jungclaus JH, Marotzke J (2011) Recovery mechanisms of Arctic summer sea ice. Geophys Res Lett. doi:10.102 9/2010GL045698

Valcke S (2006) OASIS3 User Guide (prism_2-5). PRISM Report Series, No 2, 6th edn. http://www.prism.enes.org/Publications/ Reports/all_editions/index.php£report02

Vancoppenolle M, Bouillon S, Fichefet T, Goosse H, Lecomte O, Morales Maqueda MA, Madec G (2012) LIM The 
Louvain-la-Neuve sea Ice Model. Note du Pole de modélisation, Institut Pierre-Simon Laplace (IPSL), France

Vavrus SJ, Holland MJ, Jahn A, Bailey DA, Blazey BA (2012) Twenty-first century arctic climate change in CCSM4. J Clim 25:2696-2710. doi:10.1175/JCLI-D-11-00220,1

Vihma T (2014) Effects of arctic sea ice decline on weather and climate: a review. Surv Geophys 35:1175-1214. doi:10.1007/ s10712-014-9284-0

Vinje T, Nordlund N, Kvambeck A (1998) Monitoring ice thickness in Fram Strait. J Geophys Res 103:10437-10449

Von Storch H, Zwiers F (1999) Statistical analysis in climate research. Cambridge University Press, Cambridge
Woodgate RA, Weingartner T, Linday R (2010) The 2007 Bering Strait oceanic heat flux and anomalous Arctic sea-ice retreat. Geophys Res Lett. doi:10.1029/2009GL041621

Yang S, Christensen JH (2012) Arctic sea ice reduction and European cold winters in CMIP5 climate change experiments. Geophys Res Lett. doi:10.1029/2012GL053333

Zhang JL, Rothrock DA (2003) Modeling global sea ice with a thickness and enthalpy distribution model in generalized curvilinear coordinates. Mon Weather Rev 131:845-861 